\title{
Nitrogen acquisition by roots: physiological and developmental mechanisms ensuring plant adaptation to a fluctuating resource
}

\author{
Philippe Nacry • Eléonore Bouguyon • Alain Gojon
}

Received: 12 October 2012 / Accepted: 10 February 2013 /Published online: 21 February 2013

(C) Springer Science+Business Media Dordrecht 2013

\begin{abstract}
Background Nitrogen $(\mathrm{N})$ is one of the key mineral nutrients for plants and its availability has a major impact on their growth and development. Most often $\mathrm{N}$ resources are limiting and plants have evolved various strategies to modulate their root uptake capacity to compensate for both spatial and temporal changes in $\mathrm{N}$ availability in soil. The main $\mathrm{N}$ sources for terrestrial plants in soils of temperate regions are in decreasing order of abundance, nitrate, ammonium and amino acids. $\mathrm{N}$ uptake systems combine, for these different $\mathrm{N}$ forms, high- and low-affinity transporters belonging to multige families. Expression and activity of most uptake systems are regulated locally by the concentration of their substrate, and by a systemic feedback control exerted by whole-plant signals of $\mathrm{N}$ status, giving rise to a complex combinatory network. Besides modulation of the capacity of transport systems, plants are also able to modulate their growth and development to maintain $\mathrm{N}$ homeostasis. In particular, root system architecture is highly plastic and its changes can greatly impact $\mathrm{N}$ acquisition from soil.
\end{abstract}

Responsible Editor: Philippe Hinsinger.

P. Nacry $(\bowtie) \cdot$ E. Bouguyon $\cdot$ A. Gojon

Biochimie et Physiologie Moléculaire des Plantes, UMR

5004 CNRS/INRA/SupAgro-M/UM2, Institut de Biologie

Intégrative des Plantes Claude Grignon,

Place Viala,

34060 Montpellier Cedex 1, France

e-mail: nacry@supagro.inra.fr
Scope In this review, we aim at detailing recent advances in the identification of molecular mechanisms responsible for physiological and developmental responses of root $\mathrm{N}$ acquisition to changes in $\mathrm{N}$ availability. These mechanisms are now unravelled at an increasing rate, especially in the model plant Arabidopsis thaliana L.. Within the past decade, most root membrane transport proteins that determine $\mathrm{N}$ acquisition have been identified. More recently, molecular regulators in nitrate or ammonium sensing and signalling have been isolated, revealing common regulatory genes for transport system and root development, as well as a strong connection between $\mathrm{N}$ and hormone signalling pathways.

Conclusion Deciphering the complexity of the regulatory networks that control $\mathrm{N}$ uptake, metabolism and plant development will help understanding adaptation of plants to sub-optimal $\mathrm{N}$ availability and fluctuating environments. It will also provide solutions for addressing the major issues of pollution and economical costs related to $\mathrm{N}$ fertilizer use that threaten agricultural and ecological sustainability.

Keywords Nitrate $\cdot$ Ammonium $\cdot$ Urea $\cdot$ Nutrient sensing and signalling $\cdot$ Root uptake $\cdot$ Root development

\section{Introduction}

A major challenge for sustainable agriculture will be to increase crop production with less, or at least no 
more nitrogen $(\mathrm{N})$ fertilizer input (Tilman et al. 2002; Good et al. 2004; Gross 2012). Increasing crop production is unavoidable first to keep pace with the demographic evolution that predicts approx. 9 billions humans on Earth in 2050, and second to ensure part of the energy production through biofuels (Tilman et al. 2002; Rothstein 2007). Stabilizing, and if possible, decreasing $\mathrm{N}$ fertilizer utilization is also required to save fossil fuel and to prevent detrimental environmental consequences of excess $\mathrm{N}$ fertilizer application. Indeed, usage of $\mathrm{N}$ fertilizers is one of the most energy consuming processes associated with agriculture (Rothstein 2007, Xu et al. 2012), and its tremendous increase (9-fold world while since 1960, Hinsinger et al. 2011 ) is the main cause of a doubling in the annual input of reactive $\mathrm{N}$ species (all inorganic forms of $\mathrm{N}$ except $\mathrm{N}_{2}$ ) in the environment, as compared to pre-industrial era (Canfield et al. 2010; Diaz and Rosenberg 2008; Galloway et al. 2003 and 2008). This major anthropogenic modification of the $\mathrm{N}$ cycle has now strongly harmful consequences, because only 30-50\% of the applied fertilizer $\mathrm{N}$ are actually captured by crops (Tilman et al. 2002), with most of the rest leaching to underground water primarily in the form of nitrate $\left(\mathrm{NO}_{3}{ }^{-}\right)$, and/or being emitted in the atmosphere in the form of nitrogen oxides $\left(\mathrm{N}_{\mathrm{x}} \mathrm{O}_{\mathrm{y}}\right)$ or ammonia $\left(\mathrm{NH}_{3}\right)$. These leaching processes are not exclusive of each other, and the same $\mathrm{N}$ atom may be in turn present in the atmosphere as a gas and in water as a solute as it moves from one environmental compartment to another during its cycling (the so-called "Nitrogen cascade", Galloway et al. 2003 and 2008). Pollution of ground, surface and coastal water by $\mathrm{NO}_{3}{ }^{-}$favours eutrophication and hypoxia, with dramatic consequences for the local ecosystems that can be heavily degraded (Diaz and Rosenberg 2008; Canfield et al. 2010; Galloway et al. 2003 and 2008). Emission of $\mathrm{N}$ gaseous forms increases: i) greenhouse effect in the atmosphere (in particular nitrous oxide, which has a greenhouse effect 300 fold higher than $\mathrm{CO}_{2}$ ), ii) ozone concentration in the troposphere, and iii) formation of aerosols and fine particulate matter (Canfield et al. 2010; Galloway et al. 2003 and 2008).

As a consequence, improving $\mathrm{N}$ use efficiency by plants has emerged as a crucial goal for plant scientists, mostly through the generation of new crop varieties using genetic and/or biotechnological approaches (Good et al. 2004; Kant et al. 2011). There are several definitions of $\mathrm{N}$ use efficiency (Good et al. 2004; Xu et al. 2012), and it is usual to discriminate between $\mathrm{N}$ acquisition efficiency (the proportion of $\mathrm{N}$ taken up as compared to that available in the soil), and $\mathrm{N}$ utilization efficiency (biomass production per unit $\mathrm{N}$ taken up by the plant). At first sight, these two components are associated with different physiological processes: more active uptake systems and improved soil exploration by the roots for $\mathrm{N}$ acquisition efficiency, and stimulated photosynthetic/metabolic activity as well as efficient $\mathrm{N}$ remobilisation between organs for $\mathrm{N}$ utilization efficiency. For both aspects, however, it is known for long that plants are able to achieve improved $\mathrm{N}$ use efficiency when facing $\mathrm{N}$ limiting conditions (Kant et al. 2011). Thus, it is important for future genetic/biotechnological strategies to identify the mechanisms plants have naturally evolved to adapt to low $\mathrm{N}$ availability.

This review aims at detailing the recent advances in the understanding of the physiological and molecular mechanisms that trigger adaptive responses of the plants to sub-optimal $\mathrm{N}$ availability, in particular those involved in maintaining optimal $\mathrm{N}$ nutrition through increased $\mathrm{N}$ acquisition efficiency. Given the complexity of this topic, we will not address the role of symbioses (with $\mathrm{N}_{2}$ fixing bacteria or with mycorhizae) but concentrate only on processes occurring in plants ensuring their $\mathrm{N}$ nutrition through direct acquisition of $\mathrm{N}$ molecules by root cells from the soil solution. Therefore, a full section of this paper will be devoted to the description of the transport systems that allow these $\mathrm{N}$ molecules to be taken up by the roots. Plants react in many different ways to changes in N provision (for review: Clarkson 1985; Crawford and Glass 1998; Forde 2002; Hermans et al. 2006; Krouk et al. 2010a; Kant et al. 2011), but we will specifically focus on three types of responses for which key underlying mechanisms have been recently unravelled, namely: i) regulation of root $\mathrm{N}$ uptake systems, ii) plasticity of root system architecture, and iii) fast modulation of shoot growth. These three responses do not have the same goal. The first two generally result in an improved efficiency of root $\mathrm{N}$ uptake at low $\mathrm{N}$ availability, through both upregulation of specific high-affinity membrane transporters and enhanced foraging by the root system. The third one aims at quickly slowing down the overall $\mathrm{N}$ demand of the plant, to prevent $\mathrm{N}$ starvation when conditions for $\mathrm{N}$ uptake from the external medium are becoming unfavourable.

Despite these differences, all three responses share the common feature to be controlled by the combined 
action of external and internal signals, that are often associated with local and systemic signalling pathways in the plant, respectively (Forde 2002; Gojon et al. 2009). Most important external signals are the extra-cellular concentrations of the $\mathrm{N}$ nutrient themselves, $\mathrm{NO}_{3}{ }^{-}$and $\mathrm{NH}_{4}{ }^{+}$in particular, that are sensed locally by the roots (Crawford 1995; Stitt 1999; Tsay et al. 2011). Equally important signals are internal ones, especially those related to the overall $\mathrm{N}$ status of the whole organism that circulate between organs, and are transported downward to the roots to inform them of the $\mathrm{N}$ demand of the plant (Imsande and Touraine 1994; Liu et al. 2009). Taking into account the interplay between local and systemic signalling pathways is crucial for understanding many plant responses to $\mathrm{N}$ availability (Alvarez et al. 2012). For instance, on the one hand, systemic signalling of the whole plant $\mathrm{N}$ status is required to warrant that the roots will fulfill their specific function of $\mathrm{N}$ acquisition at the benefit of all organs. On the other hand, local signalling pathways are strictly mandatory for an autonomous behaviour of the various parts of the root system that allows overcoming the spatial heterogeneity of $\mathrm{N}$ concentration in the soil (Zhang et al. 1999; De Kroon et al. 2009). Furthermore, because local and systemic signalling pathways have often opposite actions on the same targets (e.g., local stimulation $v s$ systemic repression of lateral root growth by $\mathrm{NO}_{3}{ }^{-}$, Zhang et al. 1999, see further details below in this review), their interplay explains why an apparently similar treatment (e.g., $\mathrm{NO}_{3}{ }^{-}$supply to the plants) may lead to confusing or contradictory responses. Indeed, the complex balance between the opposite effects of local and systemic signals may yield an outcome in one direction or the other, depending on the conditions. Therefore, for many responses to $\mathrm{N}$ availability addressed in this review, special attention will be paid to differentiate between regulatory mechanisms acting either at the local or systemic level, and to understand how their cross-talk results in a relevant integrated reaction of the plant.

\section{Physiological and molecular bases of root $\mathrm{N}$ uptake}

Plants can use a wide variety of chemical $\mathrm{N}$ forms, ranging from simple inorganic $\mathrm{N}$ compounds such as ammonium $\left(\mathrm{NH}_{4}{ }^{+}\right)$and nitrate $\left(\mathrm{NO}_{3}{ }^{-}\right)$to polymeric $\mathrm{N}$ forms such as proteins. However, it is generally assumed that in almost all ecosystems, plants take up mainly $\mathrm{NH}_{4}{ }^{+}$and $\mathrm{NO}_{3}{ }^{-}$, rather than amino acids or other $\mathrm{N}$ organic forms, which apparently only play a role in extremely $\mathrm{N}$-poor and cold ecosystems where $\mathrm{N}$ mineralization from soil organic matter is very limited (Marschner 1995; Schimel and Chapin 1996). However, this assumption now needs to be revisited, because urea has become the $\mathrm{N}$ fertilizer most widely used in agriculture on a global scale (http:// faostat.fao.org), amounting to about half of total fertilizer $\mathrm{N}$ consumption. A widespread opinion is that most of the urea-N provided to crops is in fact taken up by plants in the form of $\mathrm{NH}_{4}^{+}$, following fast microbial hydrolysis of urea in the soil, and that direct urea uptake and internal hydrolysis by the plant are not significant. However, direct urea incorporation in leaves can certainly contribute to $\mathrm{N}$ intake into the plants when fertilization is performed as foliar spray. Until now, research on plant $\mathrm{N}$ acquisition had a strong focus on uptake and assimilation of $\mathrm{NO}_{3}{ }^{-}$and $\mathrm{NH}_{4}^{+}$, but physiological and molecular aspects of root uptake of urea and amino acids have recently received more attention.

The concentration of $\mathrm{NH}_{4}{ }^{+}$in the soil is generally significantly lower than that of $\mathrm{NO}_{3}{ }^{-}$(Crawford and Glass 1998; von Wirén et al. 2000a). However, it is crucial to consider the acquisition of $\mathrm{NH}_{4}{ }^{+}$alongside that of $\mathrm{NO}_{3}{ }^{-}$. Indeed, taking into account the use of urea as a main $\mathrm{N}$ fertilizer, it is likely that the importance of $\mathrm{NH}_{4}^{+}$as an $\mathrm{N}$ source has increased in agrosystems. Furthermore, even if pure $\mathrm{NH}_{4}{ }^{+}$nutrition can lead to toxicity symptoms in many herbaceous plants, a balanced $\mathrm{N}$ diet $\left(\mathrm{NO}_{3}{ }^{-}\right.$and $\left.\mathrm{NH}_{4}{ }^{+}\right)$is clearly beneficial in many species as compared to pure $\mathrm{NO}_{3}{ }^{-}$ nutrition (Forde and Clarkson 1999). Finally, even at low external concentration, $\mathrm{NH}_{4}{ }^{+}$has strong effects on the expression and/or activity of root $\mathrm{NO}_{3}{ }^{-}$transport systems, thus playing a key role in the overall regulation of $\mathrm{N}$ acquisition by the plant.

Uptake of $\mathrm{NO}_{3}{ }^{-}$or $\mathrm{NH}_{4}{ }^{+}$by the plant is the difference between influx into and efflux out of root cells (Crawford and Glass 1998; von Wirén et al. 2000a; Tsay et al. 2007). However, with the exception of specific stress conditions (e.g., Segonzac et al. 2007), net uptake of both ions is mostly determined by factors affecting influx (Lee 1993). Because most $\mathrm{N}$ transport proteins identified to date are either influx or efflux (and not bi-directional) transporters (Miller et al. 2007; Tsay et al. 2007; Wang et al. 2012), this suggests that 
influx carriers are the main control points for $\mathrm{N}$ intake into the roots. The kinetics of root $\mathrm{NO}_{3}{ }^{-}$or $\mathrm{NH}_{4}{ }^{+}$uptake (or influx) as a function of the external concentration generally display a bi-phasic pattern (Marschner 1995; Crawford and Glass 1998). In the low concentration range, high-affinity transport systems (HATS) are able to scavenge ions from the soil at concentrations as low as $1 \mu \mathrm{M}$. Both $\mathrm{NO}_{3}{ }^{-}$and $\mathrm{NH}_{4}{ }^{+}$HATS are saturable, and their activity can be modelled using the MichaelisMenten formalism (Wang et al. 1993; Filleur et al. 2001). In the high concentration range (typically $>0.5$ $1 \mathrm{mM}$ ), the activity of low-affinity transport systems (LATS) becomes evident, superimposed to that of the HATS. Unlike with the HATS, the $\mathrm{NO}_{3}{ }^{-}$or $\mathrm{NH}_{4}{ }^{+}$uptake (or influx) mediated by the LATS is not saturable, but generally shows a linear increase with increasing external concentration (Wang et al. 1993; Touraine and Glass 1997). This has often been considered as evidence that HATS and LATS do not involve the same transporter proteins. This general HATS/LATS duality for root $\mathrm{N}$ uptake has been consistently observed in almost all species investigated to date, and under most environmental conditions (Doddema et Telkamp 1979, Wang et al. 1993; Vidmar et al. 2000, Santi et al. 2003 Tong et al. 2005).

The relative contributions of HATS and LATS to the overall $\mathrm{N}$ uptake are clearly different between $\mathrm{NO}_{3}{ }^{-}$and $\mathrm{NH}_{4}{ }^{+}$. In most soils, free $\mathrm{NH}_{4}{ }^{+}$is found at low concentrations, well below $1 \mathrm{mM}$ (vonWirén et al. 2000a). Therefore, it is anticipated that for this $\mathrm{N}$ source, the HATS plays a predominant role over the LATS for nutrition of the plant. This is markedly different for $\mathrm{NO}_{3}{ }^{-}$, because its concentration in the soil solution fluctuates dramatically. From few micromolar, it can reach the range of $1-10 \mathrm{mM}$ following fertilizer application or a burst in nitrification (Crawford and Glass 1998; Miller et al. 2007). Together with the differential regulation of HATS and LATS, this makes it difficult to determine the respective roles of each system in the cumulated root $\mathrm{NO}_{3}{ }^{-}$uptake by crops over long periods of time (Miller et al. 2007). Only very few attempts were made to compute HATS- or LATS-mediated $\mathrm{NO}_{3}{ }^{-}$uptake by crops over the growth cycle. Malagoli et al. (2004) found that, taking into account the seasonal pattern of $\mathrm{NO}_{3}{ }^{-}$concentration in the soil, the kinetics parameters of both HATS and LATS, as well as their regulation, the $\mathrm{NO}_{3}{ }^{-}$HATS had a major contribution to $\mathrm{N}$ acquisition by rapeseed grown in the field under regular agricultural practice.
Major insight into the individual $\mathrm{NO}_{3}{ }^{-}$and $\mathrm{NH}_{4}{ }^{+}$carrier proteins responsible for $\mathrm{N}$ uptake by plant roots has been done recently (Tsay et al. 2007; Gojon et al. 2009). The main structural components of both $\mathrm{NO}_{3}{ }^{-}$and $\mathrm{NH}_{4}{ }^{+}$ HATS have been identified and functionally characterized in Arabidopsis thaliana (Fig. 1), and this work is now being carried out in several major crops. Additionally, low affinity $\mathrm{NO}_{3}{ }^{-}$transporters have been isolated and characterized. At the opposite, nothing is known at the molecular level concerning the LATS for $\mathrm{NH}_{4}^{+}$.

\section{Nitrate transporters}

In higher plants, membrane $\mathrm{NO}_{3}{ }^{-}$transporters or channels identified to date belong to five protein families, namely NRT1, NRT2, CLC, ALMT and SLAC1 (Forde 2000; Tsay et al. 2007; Geiger et al. 2009; Gojon et al. 2009; Sasaki et al. 2010; Barbier-Brygoo et al. 2011). However, only members of the NRT1 and NRT2 families have been shown to be involved in root $\mathrm{NO}_{3}{ }^{-}$ uptake (Fig. 1). Most of the NRT1/NRT2 transporters characterized are either high- or low-affinity transporters, thus supporting the general idea that HATS and LATS involve different carrier proteins. However, there are two exceptions to this functional separation, i.e., NRT1.1 of A.thaliana and NRT1.3 of Medicago truncatula L., which were both reported to display a dual affinity for $\mathrm{NO}_{3}{ }^{-}$(Wang et al. 1998; Liu et al. 1999; Morere-Le Paven et al. 2011).

High-affinity $\mathrm{NO}_{3}{ }^{-}$transporters were predominantly found in the NRT2 family, which comprises seven genes in A.thaliana (Orsel et al. 2002, Okamoto et al. 2003). Among them, NRT2.1 has been shown to be the major contributor, accounting on its own for up to $75 \%$, of the total HATS activity (Filleur et al. 2001; Li et al. 2007). Besides NRT2.1, two other members of the gene family, NRT2.2 and NRT2.4, were found to play a more minor role in the $\mathrm{NO}_{3}{ }^{-}$HATS (Li et al. 2007; Kiba et al. 2012). However, even if NRT2.2 represents less than $20 \%$ of the HATS activity, when NTR2.1 is mutated, NRT2.2 mRNA levels are increased up to three-fold to compensate the functional loss of NRT2.1 ( $\mathrm{Li}$ et al. 2007). Furthermore, NRT2.4 was characterized as a very high-affinity transporter, contributing significantly to the whole HATS activity at $\mathrm{NO}_{3}{ }^{-}$concentrations below $25 \mu \mathrm{M}$ (Kiba et al. 2012), whereas NRT2.1 and NRT2.2 are major players at concentrations higher than $50 \mu \mathrm{M}$ (Cerezo et al. 2001). Recent studies have suggested that NRT2.1 in Chlamydomonas reinhardtii (Zhou et al. 
Fig. 1 Schematic representation of the membrane transporters involved in the root uptake of the four major sources of nitrogen in Arabidopsis thaliana plants. Proteins are grouped according to their substrate and to their affinity for the substrate (HATS High Affinity transporters and LATS Low affinity transporters). Transporters highlighted with big letters are those that play a major role in nutrient uptake. Question marks represent unconfirmed results. Several amino acid and peptide transporters have been identified in heterologous system but there in planta function have not yet been characterised. NRT1-1 is both a LATS and HATS depending on phosphorylation of the threonine 101 residue. NAR2.1 is a protein of unknown function that is mandatory to ensure nitrate transport by NRT2 transporters

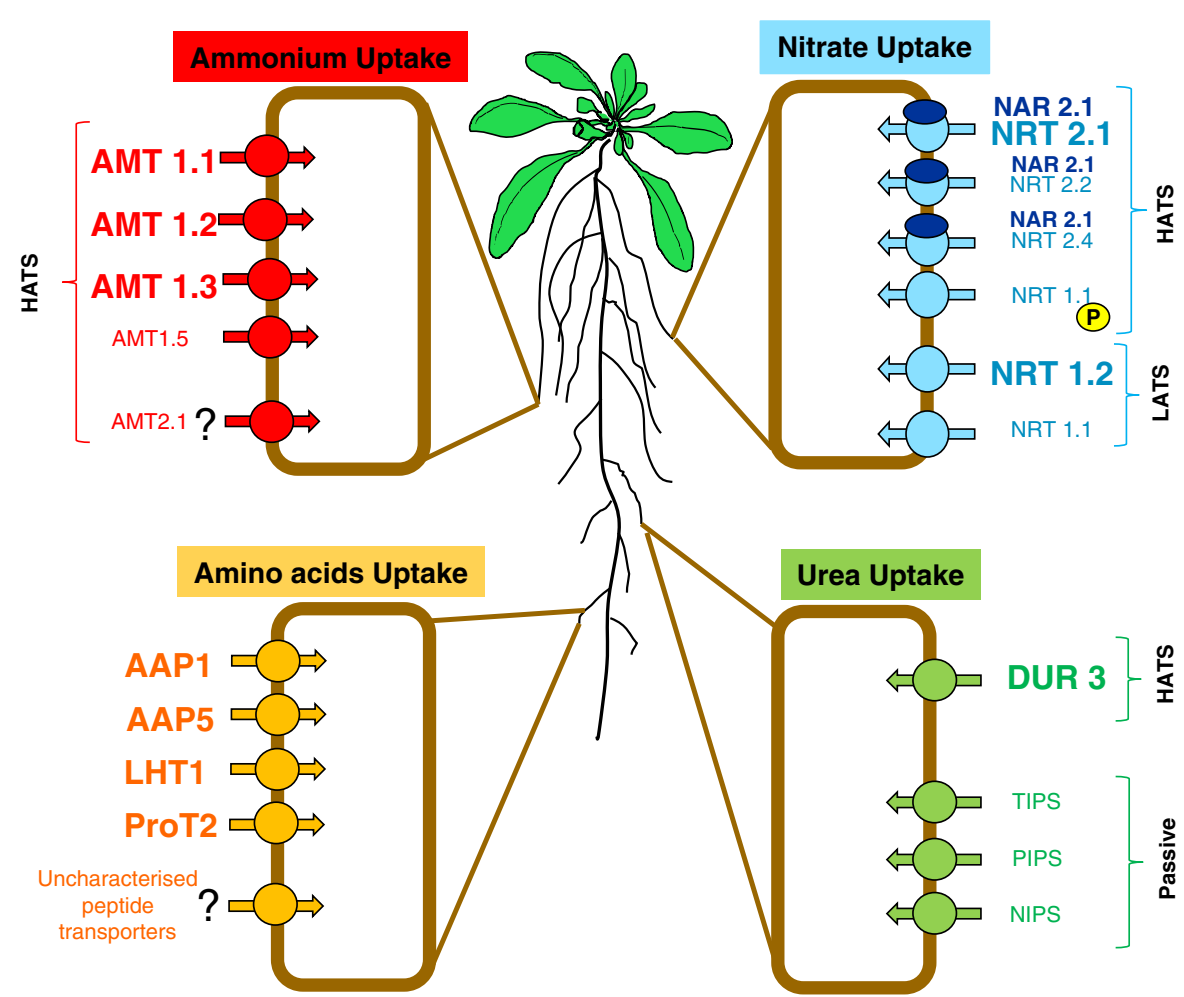

2000), barley (Hordeum vulgare L.) (Tong et al. 2005), and A.thaliana (Okamoto et al. 2006) require a second protein (NAR2/NRT3) to function as a $\mathrm{NO}_{3}{ }^{-}$transporter. NAR2 proteins have no known transport or catalytic activity, but in A.thaliana, NAR2.1 (NRT3.1) is strictly required for both expression and activity of NRT2.1 (Orsel et al. 2006; Wirth et al. 2007). Recently, Yong et al. (2010) observed that NRT2.1 and NAR2.1 proteins physically interact at the plasma membrane suggesting that the active transport system may in fact be a heterooligomer of NRT2.1 and NAR2.1. In A.thaliana, there are two NAR2 genes but to date only NAR2.1 has been found involved in HATS. Interestingly, in a nar2.1 null mutant, the HATS activity was more strongly reduced than in the nrt2.1nrt2.2 double mutant (Okamoto et al. 2006) suggesting that NAR2.1 was probably required for functionality of other NRT2 transporters. Recently Kotur et al. (2012) found that co-expression into Xenopus oocytes of AtNRT2 genes together with AtNAR2.1 resulted in a significant increases of $\mathrm{NO}_{3}{ }^{-}$uptake over and above that resulting from single injections for the seven AtNRT2 genes.
NRT2 and NAR2 genes have now been identified in many other species, such as barley (Trueman et al. 1996; Vidmar et al. 2000), rice (Oryza sativa L.) (Plett et al. 2010; Feng et al. 2011), maize (Zea mays L.), sorghum (Sorghum bicolor L.) and Brachypodium distachyon L. (Plett et al. 2010), Soybean (Glycine max L.) (Amarasighe et al. 1998) and M. truncatula (Ruffel et al. 2008). In all cases where the genome sequence is available, a multigene family was found for NRT2 proteins (with at least 3-4 members). However, NRT2 genes from grass and cereals seem to be relatively phylogenetically distant from those in A. thaliana, making it difficult to speculate about possible orthologues of the NRT2 transporters functionally charaterized in this model species (Plett et al. 2010).

Low affinity $\mathrm{NO}_{3}{ }^{-}$transporters belong to the large NRT/PTR (Peptide Transporter) family that also comprise nitrite, peptide or carboxylic acid transporters (Forde 2000; Tsay et al. 2007). In A. thaliana, 9 NRT/PTR proteins have been functionally characterized to date as $\mathrm{NO}_{3}{ }^{-}$transporters, out of the 53 members predicted from the genome sequence (Tsay et al. 2007; Gojon et al. 2009; Li et al. 2010; Wang and Tsay 
2011). However, only NRT1.1 and NRT1.2 were shown to participate in root $\mathrm{NO}_{3}{ }^{-}$uptake.

The A. thaliana NRT1.1 (initially named CHL1 that stands for CHLorate resistant mutant1) was not only the first $\mathrm{NO}_{3}{ }^{-}$transporter gene to be cloned in plants (Tsay et al. 1993), but is also the most extensively studied. Both in planta $\mathrm{NO}_{3}{ }^{-}$uptake assays in $n r t 1.1$ (chll) mutants and in NRT1.1-injected Xenopus oocytes initially identified NRT1.1 as a low affinity $\mathrm{NO}_{3}{ }^{-}$transporter participating in the LATS (Doddema and Telkamp 1979; Tsay et al. 1993; Huang et al. 1996; Touraine and Glass 1997). However, Wang et al. (1998) later showed that high-affinity $\mathrm{NO}_{3}{ }^{-}$uptake by the HATS was also defective in chll mutant. Furthermore, Xenopus oocytes expressing NRT1.1 actually exhibit two phases of $\mathrm{NO}_{3}{ }^{-}$uptake kinetics, indicating that this protein has a unique feature of a dual-affinity $\mathrm{NO}_{3}{ }^{-}$transporter (Liu et al. 1999). It displays highaffinity transport activity when phosphorylated at the T101 residue, while the non-phosphorylated form is a low-affinity transporter (Liu and Tsay 2003; Ho et al. 2009). On the contrary, NRT1.2 is a strict low-affinity $\mathrm{NO}_{3}{ }^{-}$transporter (Huang et al. 1999). It is located in the root epidermis and cortex, and underexpressors or knockout mutants have a reduced LATS activity (Huang et al. 1999; Krouk et al. 2006). Other contributors to the low-affinity root $\mathrm{NO}_{3}{ }^{-}$uptake in $A$. thaliana still await identification because NRT1.1 and NRT1.2 alone cannot account for the total LATS activity. Indeed, knockout mutation of NRT1.2 results only in a limited inhibition of the LATS activity (Huang et al. 1999; Krouk et al. 2006), and chll mutants display defects in either HATS or LATS activity only in a limited range of experimental conditions, such as mixed $\mathrm{NH}_{4}{ }^{+} / \mathrm{NO}_{3}{ }^{-}$nutrition where $\mathrm{NH}_{4}{ }^{+}$, and not $\mathrm{NO}_{3}{ }^{-}$, is actually the main $\mathrm{N}$ form taken up by the plant (Touraine and Glass 1997; Wang et al. 1998).

Close homologues of the A.thaliana NRT1 have been identified in cereals including rice (Lin et al. 2000; Tsay et al. 2007; Plett et al. 2010), maize (Santi et al. 2003; Plett et al. 2010), and barley (West et al. 1998; Vidmar et al. 2000; Tong et al. 2005), and in other species like Tomato (Solanum lycopersicum L.) (Lauter et al. 1996) or M. truncatula (Ruffel et al. 2008, Morère-Le Paven et al. 2011). However, most of the studies on the activity and regulation of NRT1 transport proteins have been conducted in A. thaliana, and a huge work of functional characterization remains to be done in other species.
Ammonium transporters

The root uptake of $\mathrm{NH}_{4}{ }^{+}$involves the AMT family of high-affinity transporters (Fig. 1), which is part of a larger group of $\mathrm{NH}_{4}^{+}$permeases of the Ammonium Transporter/Methylammonium Permease/Rhesus (AMT/MEP/Rh) family (von Wirén and Merrick 2004). Heterologous expression of selected plant AMTs in yeast or Xenopus oocytes indicate they function as high-affinity transporters, most probably as $\mathrm{NH}_{4}^{+}$ uniporters that transport $\mathrm{NH}_{4}{ }^{+}$along the electrochemical potential gradient (Ninnemann et al. 1994; Gazzarini et al. 1999; Ludewig et al. 2002, 2003). A. thaliana possesses a family of six AMT-type $\mathrm{NH}_{4}{ }^{+}$transporters, where AMT1.1-AMT1.5 belong to the AMT1 clade, while AMT2.1 is more closely related to the MEP/AMTB subfamily found in yeast and bacteria (Ludewig et al. 2001). With the exception of AMT1.4, all the $A M T$ genes are expressed in roots (Gazzarini et al. 1999; Yuan et al. 2007, 2009). AMT1.1 and AMT1.3 are localized in the plasma membrane of epidermal and cortical root cells and have each been shown to be individually responsible for $\sim 30 \%$ of the $\mathrm{NH}_{4}{ }^{+}$HATS uptake capacity (Kaiser et al. 2002; Loqué et al. 2006). AMT1.2 is a lower affinity transporter expressed in endodermal and cortical cells and is thought to play a role either in uptake and retrieval of ammonium from the root apoplast (Yuan et al. 2007) or in $\mathrm{NH}_{4}^{+}$transfer into the vasculature (Neuhäuser et al. 2007). AMT2.1 is also expressed in the vasculature, cortical and root tip cells, but seems to play a marginal role in $\mathrm{NH}_{4}{ }^{+}$uptake from the soil solution (Sohlenkamp et al. 2000; Yuan et al. 2007). Finally, Yuan et al. (2007), using a quadruple mutant knockout (qko) for AMT1.1, AMT1.2, AMT1.3 and $A M T 2.1$, and transgenic lines complemented with the individual $A M T$ genes, showed that most of the $\mathrm{NH}_{4}{ }^{+}$ HATS capacity of $\mathrm{N}$-starved wild type plants is accounted for by a relatively similar and additive contribution of AMT1.1, AMT1.2 and AMT1.3, with only 5$10 \%$ of this capacity possibly attributable to AMT1.5 that is also localized in the plasma membrane of the epidermal cells, including root hairs (Yuan et al. 2007).

The AMT family has also been investigated in other species than A. thaliana, such as tomato (Lauter et al. 1996), rice (Kumar et al. 2003), Lotus japonicus L. (D’Apuzzo et al. 2004), and Citrus sinensis L. (Camanes et al. 2007). In rice, 10 putative OSAMT transporter genes were found, distributed into four different sub-families, OsAMT1 to OsAMT4 (Suenaga et 
al. 2003). To date, the three OSAMT1 genes have been most studied, and found to be significantly or predominantly expressed in the roots (Kumar et al. 2003; Sonoda et al. 2003a). Overexpression of OsAMT1.1 sometimes resulted in an enhanced $\mathrm{NH}_{4}{ }^{+}$influx in the roots, depending on genotype background and experimental conditions, thus supporting its role in $\mathrm{NH}_{4}^{+}$acquisition by the plant (Hoque et al. 2006; Kumar et al. 2006). However, OsAMT1.1 overexpressors often show reduced growth as compared to wildtype plants when supplied with $\mathrm{NH}_{4}{ }^{+}$as sole $\mathrm{N}$ source, possibly indicating toxicity effects of excessive $\mathrm{NH}_{4}{ }^{+}$ intake (Hoque et al. 2006; Kumar et al. 2006).

\section{Organic $\mathrm{N}$ transporters}

The quantitative contribution of organic $\mathrm{N}$ sources in the soil to plant $\mathrm{N}$ nutrition is still under debate (Nasholm et al. 2009) but all tested plant species have been found to possess the capacity to take up urea and amino acids. A. thaliana plants possess a high-affinity urea transporter (DUR3, Fig. 1) that is involved in taking up environmental urea but may also mediate internal urea transport (Liu et al. 2003a; Kojima et al. 2007). DUR3 was identified by its similarity to the urea transporter of Saccharomyces cerevisiae (ScDUR3), and was shown to account for most of the root urea HATS activity (Kojima et al. 2007). Orthologs of AtDUR3 are present throughout the green lineage from algae to higher plants, mostly encoded by single copy genes (Wang et al. 2008). The protein is expressed at the plasma membrane of root epidermal cells especially in nitrogen-starved plants and the promoter is responsive to urea in the absence of other nitrogen sources which is consistent with its role as urea transporter (Kojima et al. 2007; Merigout et al. 2008). Passive urea transport mediated by aquaporins (TIPs PIPs and NIPs) has been reported (Witte 2011). According to their location in the tonoplast membrane, TIPs proteins might be involved in urea storage in vacuoles rather than in uptake from soil (Liu et al. 2003b). On the contrary, two NIPS (At2g29870 and At2g34390), that are among the few genes that are specifically upregulated by urea, have been proposed to participate to soil urea uptake (Merigout et al. 2008) but further characterization remains to be done to better understand their function.

Early work initiated in the 1980s suggested that amino acid transport in plants was mediated either by a single system (Reihnold and Kaplan 1984), or by two major transport systems for neutral/acidic or basic amino acids, respectively (Datko and Mudd 1985; Schobert and Komor 1987). Later on, molecular approaches initiated by Frommer et al. (1993) who cloned a plant amino acid transporter gene (AAP1), and availability of full genome sequences, have allowed to grasp the abundance of amino acid transporters in plant genomes. They belong to at least five gene families, comprising no less than 67, 134 and 96 putative amino acid transporter genes in A. thaliana, Poplar (Populus trichocarpa L.) and rice, respectively (rewiewed by Rentsch et al. 2007). The in planta function of this multitude of different transporters is far from being characterized (Tegeder 2012). However, AAP1 (Lee et al. 2007), AAP5 (Svennerstam et al. 2008), LHT1 (Svennerstam et al. 2007) and ProT2 (Lehmann et al. 2011) have been identified as crucial components of amino acid root uptake in $A$. thaliana, within the concentration ranges relevant for field conditions. Efflux of amino acids from roots has been shown to occur in several species (Paynel et al. 2001; Phillips et al. 2004, 2006; Lesuffleur et al. 2007). The molecular mechanisms involved remain to be elucidated. Hypothetically, energydependent carriers in the plasma membrane may mediate this transport. However, amino acid efflux may simply represent leakage from roots, as a result of the high concentration gradient across the plasmalemma (e.g., 1$10 \mathrm{mM}$ inside the cell against $0.1-10 \mu \mathrm{M}$ outside, Näsholm et al. 2009). In this context, it has been suggested that root amino acid uptake systems may primarily be involved in retrieval of amino acids that have leaked out of the cells (Jones et al. 2005).

\section{Regulatory mechanisms affecting root $\mathrm{N}$ uptake systems}

Root $\mathrm{N}$ uptake is strongly regulated in response to changes in the external $\mathrm{N}$ availability or in the $\mathrm{N}$ demand of the whole plant. Many of the transport systems detailed above are subjected to such regulation. However, a general conclusion arising from most studies is that the HATS for the various $\mathrm{N}$ sources are particularly responsive, and display a much higher flexibility than the corresponding LATS. There are two major mechanisms that co-ordinately act to modulate root $\mathrm{N}$ uptake as a function of external $\mathrm{N}$ supply or internal N demand (Crawford and Glass 1998; 
Gojon et al. 2009). The first one relates to the direct effect of the $\mathrm{N}$ sources themselves that are perceived by specific sensing systems (e.g., $\mathrm{NO}_{3}{ }^{-}$or $\mathrm{NH}_{4}{ }^{+}$acting as signal molecules). Depending on the transport system, this may lead to the induction or the repression of the uptake systems. The second mechanism is a feedback repression exerted by high $\mathrm{N}$ status of the whole plant, that downregulates high-affinity uptake systems under $\mathrm{N}$ satiety conditions. This repression is relieved when plants experience $\mathrm{N}$ limitation, resulting in a strong increase in HATS capacity that improves $\mathrm{N}$ uptake efficiency.

Induction of transporter gene expression by $\mathrm{NO}_{3}{ }^{-}, \mathrm{NH}_{4}{ }^{+}$or urea

Nitrate is not only a nutrient but also acts as a potent signal molecule governing many aspects of plant physiology and development (Crawford 1995; Stitt 1999; Krouk et al. 2010a). A striking illustration of the signalling action of $\mathrm{NO}_{3}{ }^{-}$is that its supply to plants grown on other $\mathrm{N}$ sources, or previously $\mathrm{N}$-starved for several days, results in a massive reprogrammation of the genome expression (Wang et al. 2000, 2003; Scheible et al. 2004). Up to $10 \%$ of the transcriptome is responsive to $\mathrm{NO}_{3}{ }^{-}$(Krouk et al. 2010a), and for many genes, it has been clearly established that $\mathrm{NO}_{3}{ }^{-}$per se is the signal, because these genes are still $\mathrm{NO}_{3}{ }^{-}$-regulated in mutants deficient in nitrate reductase, the first enzyme of the $\mathrm{NO}_{3}{ }^{-}$assimilation pathway (Wang et al. 2004). An exhaustive analysis of the far-reaching consequences of $\mathrm{NO}_{3}{ }^{-}$signalling on plant physiology is beyond the scope of this review. However, many studies have highlighted that major targets of $\mathrm{NO}_{3}{ }^{-}$signalling pathways are the transport systems participating in root $\mathrm{NO}_{3}{ }^{-}$uptake (Forde 2002; Tsay et al. 2007; Gojon et al. 2009). It is known for 40 years that $\mathrm{NO}_{3}{ }^{-}$supply leads to an induction of root $\mathrm{NO}_{3}{ }^{-}$uptake in various plant species. This was first documented by Jackson et al. (1972) who observed in wheat (Triticum aestivum L.), maize and tobacco (Nicotiana tabacum L.) that $\mathrm{NO}_{3}{ }^{-}$ uptake rate was gradually increasing upon $\mathrm{NO}_{3}{ }^{-}$supply. Extensive molecular studies in A. thaliana have shown that this is associated with the induction of several $\mathrm{NO}_{3}{ }^{-}$ transporter genes (Fig. 2), especially those encoding components of the HATS such as NRT1.1, NRT2.1 and NRT2.2 (Tsay et al. 1993; Filleur and Daniel-vedele 1999; Lejay et al. 1999; Zhuo et al. 1999; Okamoto et al. 2003). A similar feature has also been reported in other plant species such as tomato (Lauter et al. 1996), soybean (Amarasinghe et al. 1998), barley (Vidmar et al. 2000), maize (Santi et al. 2003) or rice (Feng et al. 2011). However, uninduced plants still keep a basal capacity to take up $\mathrm{NO}_{3}{ }^{-}$in the low concentration range, and not all NRT2 genes are induced by $\mathrm{NO}_{3}{ }^{-}$(Crawford and Glass 1998; Okamoto et al. 2003; Kiba et al. 2012). This gave rise to the hypothesis that the $\mathrm{NO}_{3}{ }^{-}$HATS comprises in fact two different components, a constitutive HATS (cHATS), present and active even in the absence of $\mathrm{NO}_{3}{ }^{-}$, and an inducible (iHATS) that is only expressed or activated after $\mathrm{NO}_{3}{ }^{-}$pretreatment. In $A$. thaliana, NRT2.1 plays a predominant role in the iHATS because null $n r t 2.1$ mutants have lost most of the stimulation of high-affinity $\mathrm{NO}_{3}{ }^{-}$uptake by $\mathrm{NO}_{3}{ }^{-}$ (Cerezo et al. 2001; Li et al. 2007). Induction of $\mathrm{NO}_{3}{ }^{-}$ transporter genes by $\mathrm{NO}_{3}{ }^{-}$is fast, being most often recorded as soon as 20-30 min after $\mathrm{NO}_{3}{ }^{-}$supply (Tsay et al. 1993; Wang et al. 2000; Scheible et al. 2004). It is well established from "split-root" experiments (in which only a part of the root system can be supplied with $\mathrm{NO}_{3}{ }^{-}$) that induction by $\mathrm{NO}_{3}{ }^{-}$is a local process (Burns 1991; Robinson 1994; Ohlen and Larsson 1992; Gansel et al. 2001). Although it can be triggered by $\mathrm{NO}_{3}{ }^{-}$concentrations as low as $10 \mu \mathrm{M}$, it is concentration-dependent, in a sometimes complex manner. For NRT2.1, two phases can be distinguished that closely mimic those found for $\mathrm{NO}_{3}{ }^{-}$uptake in the roots (Hu et al. 2009; Ho et al. 2009): a 'high-affinity' phase that leads to a moderate induction of the gene in the low $\mathrm{NO}_{3}{ }^{-}$concentration range, and a 'low-affinity phase', resulting in a further increase in NRT2.1 expression at high $\mathrm{NO}_{3}{ }^{-}$concentration. In contrast to the HATS, the $\mathrm{NO}_{3}{ }^{-}$LATS shows little induction in response to $\mathrm{NO}_{3}{ }^{-}$ supply (Crawford and Glass 1998). Accordingly, only the dual-affinity NRT1.1 transporter gene has been reported to be $\mathrm{NO}_{3}{ }^{-}$inducible in $A$. thaliana, while other NRT1 genes, including NRT1.2 that encodes an important component of the LATS, were found to be constitutively expressed, regardless of the presence or absence of $\mathrm{NO}_{3}{ }^{-}$(Huang et al. 1999; Okamoto et al. 2003).

The molecular mechanisms involved in the $\mathrm{NO}_{3}{ }^{-}$ regulation of $\mathrm{NO}_{3}{ }^{-}$transporter genes are far from being understood but at least three genes, namely NRT1.1, NLP7 and CIPK8, were shown to be required for proper induction of $\mathrm{NO}_{3}{ }^{-}$transporter genes in $A$. thaliana (Fig. 3).

Quite unexpectedly, the NRT1.1 $\mathrm{NO}_{3}{ }^{-}$transporter plays a pivotal role in many $\mathrm{NO}_{3}{ }^{-}$signalling responses 
(Fig. 3), supporting the hypothesis that it may in fact be a $\mathrm{NO}_{3}{ }^{-}$'transceptor', i.e., a protein ensuring a dual transport and sensing function (Gojon et al. 2011). In particular, NRT1.1 was found to trigger the induction of NRT2.1 expression by $\mathrm{NO}_{3}{ }^{-}$(Ho et al. 2009; Wang et al. 2009). Knockout mutation of NRT1.1 almost totally prevents the increase in NRT2.1 mRNA accumulation in response to provision of $\mathrm{NO}_{3}{ }^{-}$for $30 \mathrm{~min}$, following growth of the plants on $\mathrm{NH}_{4}{ }^{+}$-succinate as sole $\mathrm{N}$ source (Ho et al. 2009). However, this does not lead to a complete lack of NRT2.1 expression in nrt1.1 mutants. First, NRT1.1 mutation only delays induction of NRT2.1 that is effective after several hours as compared to $0.5-1 \mathrm{~h}$ in wild type plants. Second, the involvement of NRT1.1 in NRT2.1 induction appears to be dependent on prior experimental conditions. Indeed, $n r t 1.1$ mutants display an unaffected induction of NRT2.1 expression as compared to wild type plants when the $\mathrm{NO}_{3}{ }^{-}$treatment is performed on plants previously subjected to $\mathrm{N}$ deprivation for several days indicating that NRT1.1 is not the only $\mathrm{NO}_{3}{ }^{-}$sensor that regulates NRT2-1 expression (Muños et al. 2004; Wang et al. 2009). A convincing evidence supporting the direct role of NRT1.1 as a $\mathrm{NO}_{3}{ }^{-}$sensor is the fact that point mutations in the protein uncouple transport and signalling activities. For instance, the P492L mutation suppresses $\mathrm{NO}_{3}{ }^{-}$transport by NRT1.1, but not the NRT1.1-dependent induction of NRT2.1 by $\mathrm{NO}_{3}{ }^{-}$ (Ho et al. 2009). Also, the T101A mutation that prevents phosphorylation of the protein and inhibits $\mathrm{NO}_{3}{ }^{-}$ transport by NRT1.1 at low $\mathrm{NO}_{3}{ }^{-}$concentrations (Liu and Tsay 2003) actually stimulates NRT2.1 induction under the same range of $\mathrm{NO}_{3}{ }^{-}$concentrations (Ho et al. 2009). These data show that there is no direct relationship between $\mathrm{NO}_{3}{ }^{-}$signalling and $\mathrm{NO}_{3}{ }^{-}$transport by NRT1.1 and that loss of $\mathrm{NO}_{3}{ }^{-}$signalling in nrt1.1 KO mutants is not due to impaired uptake of the $\mathrm{NO}_{3}{ }^{-}$signal molecule. The actual mechanism by which NRT1.1 triggers $\mathrm{NO}_{3}{ }^{-}$signalling for induction of the NRT2.1 gene remains however to be elucidated.

NLP7 is a putative transcription factor of the NINlike (Nodule-INception-like) family of $A$. thaliana. These proteins are homologous to the NIT2 transcription factor of $C$. reinhardtii that was shown to be a main player in $\mathrm{NO}_{3}{ }^{-}$signalling, strictly required for induction of the nitrate reductase NIA gene (Camargo et al. 2007). Among the 7 members of the NLP family, NLP7 appears to be specifically involved in $\mathrm{NO}_{3}{ }^{-}$ signalling, and necessary for full induction of NIA1,
NIA2, NRT2.1 and NRT2.2 genes (Castaings et al. 2009). However, the $\mathrm{NO}_{3}{ }^{-}$response of these genes is not totally impaired in $n l p 7$ knockout mutants, suggesting that unlike in $C$. reinahdtii, $\mathrm{NO}_{3}{ }^{-}$induction of gene expression in plants is not dependent on a single signalling pathway.

Finally, CIPK8 is a calcineurin B-like interacting protein kinase, which is inducible by $\mathrm{NO}_{3}{ }^{-}$at the gene level in a partially NRT1.1-dependent manner (Hu et al. 2009). Interestingly, CIPK 8 also contributes to the induction by $\mathrm{NO}_{3}{ }^{-}$of several $\mathrm{NO}_{3}{ }^{-}$uptake and assimilation-related genes, including NRT2.1 and NRT1.1. This mutual dependence of NRT1.1 and CIPK8 for their $\mathrm{NO}_{3}{ }^{-}$induction suggests a positive feedback loop in the $\mathrm{NO}_{3}{ }^{-}$signalling pathway governing expression of $\mathrm{NO}_{3}{ }^{-}$-responsive genes.

It is still unclear whether $\mathrm{NH}_{4}^{+}$per se also has a similar signalling action in inducing its own transport systems (AMTs). Like that of $\mathrm{NO}_{3}^{-}$, root uptake of $\mathrm{NH}_{4}{ }^{+}$has been reported to be transiently stimulated after reintroduction of $\mathrm{NH}_{4}{ }^{+}$following a period of low $\mathrm{N}$ provision (Mack and Tischner 1994). However, in most plant species investigated to date, expression of $A M T$ genes is repressed rather than induced by $\mathrm{NH}_{4}{ }^{+}$(see below), but there are exceptions to this general trend. In tomato for instance, while LeAMT1.1 mRNA is most abundant when $\mathrm{N}$ availability is limited, transcription of LeAMT1.2 is clearly upregulated by the supply of $\mathrm{NH}_{4}^{+}$ (Lauter et al. 1996, Von Wiren et al. 2000b). In rice, expression of both OSAMT1;1 and OSAMT1;2 is stimulated by $\mathrm{NH}_{4}{ }^{+}$, and accordingly repressed by $\mathrm{N}$ starvation (Sonoda et al. 2003a). Nevertheless, this does not appear to be due to specific $\mathrm{NH}_{4}^{+}$signalling, because glutamine had the same positive effect and glutamine synthetase inhibitors prevented OSAMT1;1 and OSAMT1;2 induction by $\mathrm{NH}_{4}{ }^{+}$. Thus, these two genes seem to be regulated by downstream metabolites of $\mathrm{NH}_{4}{ }^{+}$assimilation, possibly by glutamine itself since glutamine concentration in root tissues correlated well with OsAMT1s expression (Sonoda et al. 2003b). These authors (Sonoda et al. 2003b) proposed that the difference might come from the fact that contrary to $A$. thaliana and tomato, rice is adapted to flooded and hypoxic medium, so that $\mathrm{NH}_{4}^{+}$nutrition prevails. Concerning urea, molecular analysis of AtDUR3 expression showed that its expression is downregulated by $\mathrm{NO}_{3}{ }^{-}$and $\mathrm{NH}_{4}{ }^{+}$, but markedly induced by supply of urea (Fig. 3, Kojima et al. 2007). Yet no further progress had been done to delineate this complex regulation. 
Repression of transporter gene expression by $\mathrm{N}$ metabolites

A major regulation of root $\mathrm{N}$ uptake systems is their feedback repression by signals of $\mathrm{N}$ satiety. Indeed, numerous studies on various plant species have shown that the root uptake capacity for $\mathrm{NO}_{3}{ }^{-}, \mathrm{NH}_{4}{ }^{+}$and urea is strongly downregulated when plants are subjected to ample $\mathrm{N}$ provision, whereas $\mathrm{N}$ starvation or $\mathrm{N}$ limitation results in the opposite response (Crawford and Glass 1998, von Wirén et al. 2000a, b; Kojima et al. 2007; Tsay et al. 2007; Gojon et al. 2009). Very little is known about any regulation of organic $\mathrm{N}$ uptake. However, studies based on mixed (organic/inorganic) N nutrition showed that uptake rates of amino acids are very little affected by $\mathrm{N}$ treatments, compared to $\mathrm{NO}_{3}{ }^{-}$and $\mathrm{NH}_{4}{ }^{+}$ uptake rates, that were strongly responsive both in soil (Ohlund and Nasholm 2001) or in solution (Thornton and Robison 2005). Concerning root $\mathrm{NO}_{3}{ }^{-}$transport systems, split-root experiments have demonstrated that this regulation relies on systemic signalling pathways, modulating $\mathrm{NO}_{3}{ }^{-}$uptake rate as a function of the $\mathrm{N}$ status of the whole plant. For instance, $\mathrm{N}$ deprivation of one side of the split-root system leads to a compensatory stimulation of $\mathrm{NO}_{3}{ }^{-}$uptake by the other side of the root system that remains under unmodified $\mathrm{NO}_{3}{ }^{-}$ supply (Burns 1991; Robinson 1994; Ohlen and Larsson 1992; Gansel et al. 2001). As long as the proportion of the root system subjected to $\mathrm{N}$ deprivation does not remain too high (e.g., $<50-75 \%$ ), the other roots can within a few days fully compensate for the lack of $\mathrm{NO}_{3}{ }^{-}$uptake by N-starved roots, to restore total $\mathrm{N}$ acquisition at the level measured on the whole root system prior to the localized $\mathrm{N}$ deprivation treatment (Gansel et al. 2001; Ruffel et al. 2008). Therefore, even in roots well fed with $\mathrm{N}, \mathrm{NO}_{3}{ }^{-}$uptake systems can react to the $\mathrm{N}$ starvation experienced by other organs, indicating long-distance signalling of $\mathrm{N}$ limitation. This regulation is thought to have a crucial physiological significance because it is certainly the means by which plants are able to rapidly adjust their $\mathrm{N}$ uptake efficiency according to the changes in their $\mathrm{N}$ demand for growth.

For both $\mathrm{NO}_{3}{ }^{-}$and $\mathrm{NH}_{4}{ }^{+}$, the HATS appears to be the main target of the feedback regulation by the $\mathrm{N}$ status of the plant. Indeed, unlike that of the HATS, the LATS activity is generally not markedly repressed or stimulated by high or low N supply, respectively (Wang et al. 1993; Lejay et al. 1999). Molecular data are in agreement with this conclusion. In most species investigated, specific members of the NRT2 and AMT1 families of high-affinity transporters are strongly modulated at the transcript level in response to the changes in $\mathrm{N}$ status of the plant (Fig. 2). In $A$. thaliana, NRT2.1, NRT2.2, AMT1.1, AMT1.2 and $A M T 1.3$ genes are all strongly derepressed by $\mathrm{N}$ starvation, with an increase in mRNA level in the roots that can be $>10$-fold as compared to that in well-fed plants (Gazzarini et al. 1999; Lejay et al. 1999; Zhuo et al. 1999). This is also true for the high-affinity urea transporter gene DUR3 (Kojima et al. 2007). Moreover, most of these genes were shown to be actually responsible for the modulation of the HATS by the $\mathrm{N}$ demand of the plant. Indeed, knockout mutants for both NRT2.1 and NRT2.2, or for the three AMT1.1-3 genes show little increase in $\mathrm{NO}_{3}{ }^{-}$or $\mathrm{NH}_{4}{ }^{+}$ HATS activity, respectively, in response to $\mathrm{N}$ starvation (Cerezo et al. 2001; Loqué et al. 2006; Yuan et al. 2007). For NRT2.1, AMT1.1, AMT1.3 and DUR3, promoter-reporter gene fusions showed that regulation occurs at the transcriptional level (Nazoa et al. 2003; Loqué et al. 2006; Kojima et al. 2007; Girin et al. 2007, 2010). For NRT2.1, split-root experiments indicated that regulation of its expression is due to systemic signalling, since this gene is upregulated in roots still fed with $\mathrm{NO}_{3}{ }^{-}$in response to a localized $\mathrm{N}$ starvation treatment on another portion of the root system (Gansel et al. 2001). Studies on other species than $A$. thaliana have confirmed that NRT2 and AMT1 genes are under feedback repression by high $\mathrm{N}$ status of the plant: HvNRT2.x in barley (Vidmar et al. 2000), NpNRT2.1 in Nicotiana Plumbaginifolia L. (Krapp et al. 1998), ZmRNT2.1 in maize (Santi et al. 2003), OSNRT2.genes in rice (Cai et al. 2008), LeNRT2. genes in tomato (Lauter et al. 1996) or MtNRT2. genes in M. truncatula (Ruffel et al. 2008). Concerning the low-affinity $\mathrm{NO}_{3}{ }^{-}$transporters genes, neither NRT1.1 nor NRT1.2 was shown to be upregulated by $\mathrm{N}$ starvation in A thaliana (Huang et al. 1999; Lejay et al. 1999), in agreement with the observations based on measurements of the $\mathrm{NO}_{3}{ }^{-}$LATS activity..

Although the systemic control exerted on root $\mathrm{NO}_{3}{ }^{-}$and $\mathrm{NH}_{4}{ }^{+}$transporters has been clearly defined at the physiological level, and further documented by the identification of the transporter genes targeted by this control, almost nothing is known at the molecular level concerning the regulatory mechanisms themselves. To date, only a single gene, namely HNI9/IWS1 of $A$. thaliana, was shown to participate in the signalling 
Fig. 2 Nitrogen regulation of the transporter genes involved in the root uptake of the four major sources of nitrogen in Arabidopsis thaliana plants. Green and red lines figure positive and negative effects, respectively. These effects refer to changes in transcriptional activity and/or in transcript accumulation in the roots

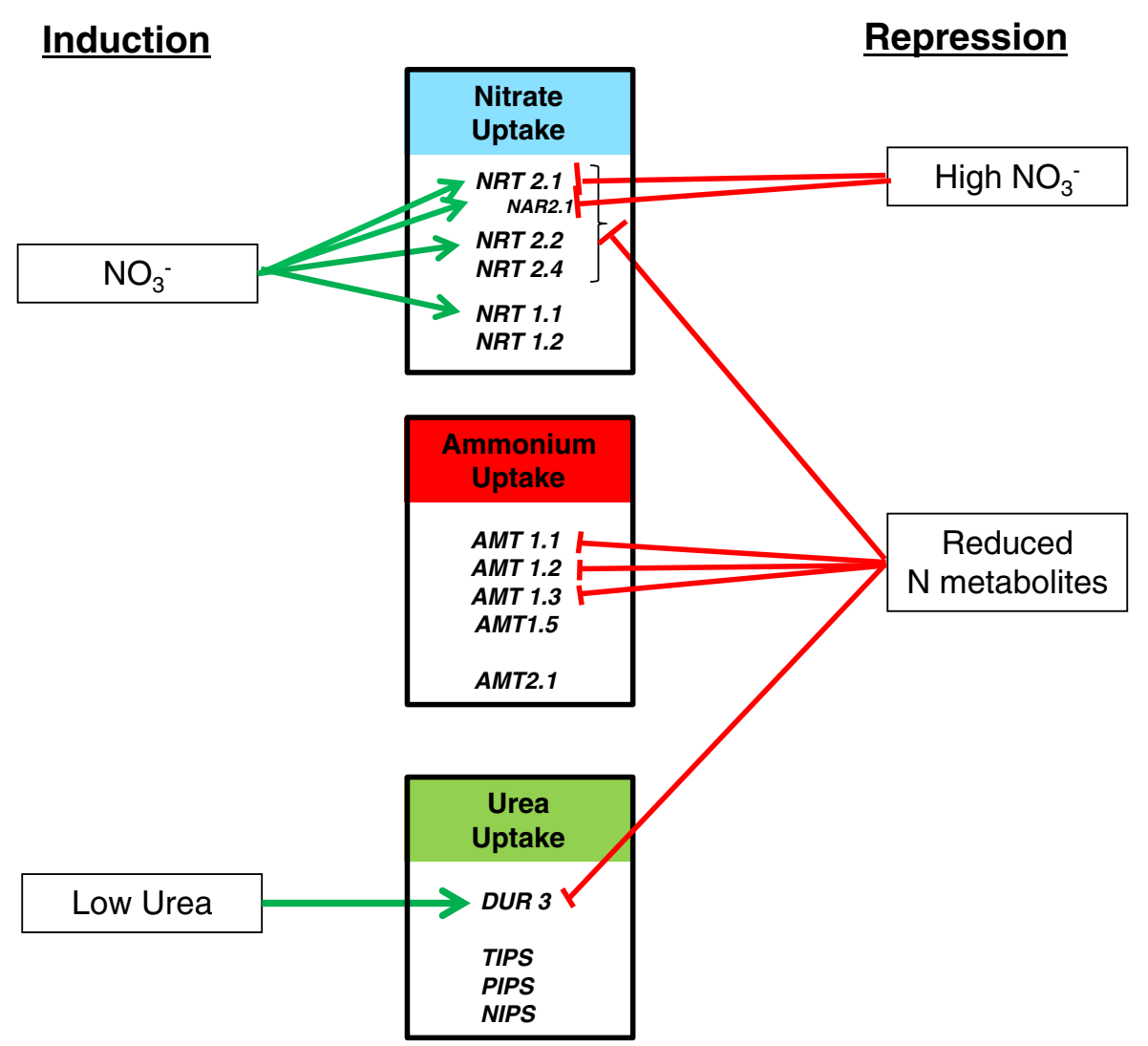

pathways governing feedback regulation of the $\mathrm{NO}_{3}{ }^{-}$ HATS by the $\mathrm{N}$ status of the whole plant (Fig. 3). HNI9/IWS1 came out of a genetic screen for mutants of $A$. thaliana impaired in the repression of the pNRT2.1::LUC reporter gene by high N supply (Girin et al. 2010). As compared to the non-mutagenized control pNRT2.1 : LUC transformants, several of these mutants, named hni (high nitrogen insensitive), display a strongly increased expression of both the pNRT2.1:: $L U C$ reporter gene and the NRT2.1 endogenous gene under repressive conditions (high $\mathrm{N}$ medium containing $10 \mathrm{mM} \mathrm{NH}_{4} \mathrm{NO}_{3}$ ). However, no difference was found for either gene between the mutants and the control line under permissive conditions (low $\mathrm{N}$ medium containing $0.3 \mathrm{mM} \mathrm{NO}_{3}{ }^{-}$), suggesting that hni mutations

\begin{tabular}{|c|}
\hline $\begin{array}{c}\text { Amino acids } \\
\text { Uptake }\end{array}$ \\
AAP1 \\
AAP5 \\
LHT1 \\
ProT2 \\
\hline
\end{tabular}

specifically altered the mechanisms involved in the feedback repression of NRT2.1 by high $\mathrm{N}$ status of the plant. Accordingly, downregulation of $\mathrm{NO}_{3}{ }^{-}$HATS activity by high $\mathrm{N}$ supply was also attenuated in the mutants (Girin et al. 2010). Positional cloning of one of the HNI genes (NHI9) revealed it encodes an IWS1 protein (Widiez et al. 2011). IWS1 proteins are evolutionary conserved components of the RNA polymerase II complex of transcription (Yoh et al. 2008). Unexpectedly, HNI9/IWS1-dependent repression of NRT2.1 expression in response to high $\mathrm{N}$ supply correlates with marked changes in histone methylation (H3K27me3 marks) at the level of the chromatin associated with NRT2.1 promoter (Widiez et al. 2011). This provides one of the first evidences that epigenetic 


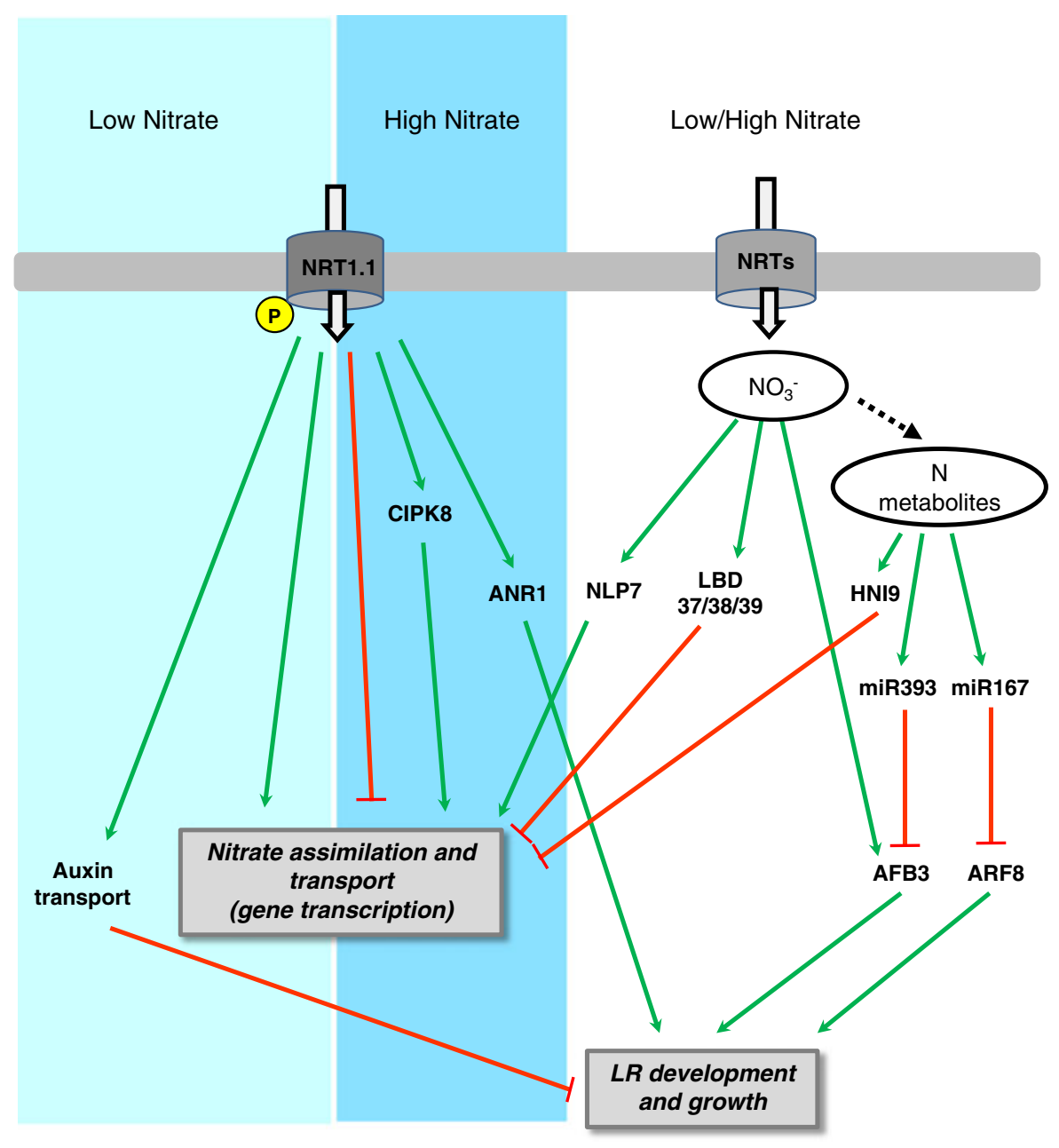

Fig. 3 Schematic representation of the $\mathrm{N}$ signalling pathways involved in the regulation of $\mathrm{N}$-dependant gene expression and root development in Arabidopsis thaliana. The molecular components identified are shown. The dual-affinity $\mathrm{NO}_{3}{ }^{-}$transporter NRT1.1 has a dual role in $\mathrm{NO}_{3}{ }^{-}$dependant regulation of gene expression and control of root development. For $\mathrm{NO}_{3}{ }^{-}$concentrations under $0.5 \mathrm{mM}$ (light blue panel) its phosphorylated form (T101 residue) modulates gene expression and represses the LR development by modulating auxin fluxes. Under $\mathrm{NO}_{3}{ }^{-}$concentration higher than $0.5 \mathrm{mM}$ (dark blue panel) the non-phosphorylated form on NRT1-1 modulates gene expression through two distinct signalling pathways, including one dependant of the proteine kinase CIPK8. NRT1-1 is also involved in the root proliferation response in $\mathrm{NO}_{3}{ }^{-}$rich patches through the transcription factor

mechanisms may be triggered by nutrient signalling pathways, and participate in the adaptive responses of the plants to nutrient limitation.

In addition to this still very limited knowledge on the molecular mechanisms involved, the exact nature
ANR1. It is still unclear which form of NRT1-1 is involved in this specific response. $\mathrm{NO}_{3}{ }^{-}$itself independently of NRT1-1, modulates gene expression in two opposite ways involving the transcription factors NLP7 and LBD. Nitrate through its assimilation products is known to repress gene expression. However, the molecular mechanism remained unclear until the identification of an epigenetic mechanism dependant of HNI9, a key component of the RNA polymerase II complex of transcription. Indeed, HNI9dependent repression of gene expression in response to high $\mathrm{N}$ supply correlates with marked changes in histone methylation of the chromatin. Nitrate and $\mathrm{N}$ metabolites affect root development through modulation of auxin perception (via AFB3) and auxin signalling (ARF8). Green and red lines indicate positive and negative effects, respectively

of the systemic signals of the whole plant $\mathrm{N}$ status remains elusive. Evidence supports the hypothesis that the satiety signal is related to the downward transport of reduced $\mathrm{N}$ metabolites. Amino acids are major constituents of both xylem and phloem saps, and it has been 
suggested that the size and/or composition of the amino acid pool cycling between roots and shoot may integrate the $\mathrm{N}$ status of all organs, and convey this information to the roots (Cooper and Clarkson 1989). The use of tobacco and $A$. thaliana nitrate reductase deficient mutants has confirmed that products of $\mathrm{NO}_{3}{ }^{-}$assimilation are involved in the feedback repression of $\mathrm{NO}_{3}{ }^{-}$uptake (Gojon et al. 1998; Lejay et al. 1999). Furthermore, exogenous supply of amino acids, especially glutamine that is a major $\mathrm{N}$ storage form and accumulates under $\mathrm{N}$ satiety conditions, represses both $\mathrm{NO}_{3}{ }^{-}$uptake and the expression of key $\mathrm{NO}_{3}{ }^{-}$transporter genes in the roots (Muller and Touraine 1992; Krapp et al. 1998; Zhuo et al. 1999; Nazoa et al. 2003). In roots of A. thaliana, transcript accumulation of the N-repressible AMT1.1 $\mathrm{NH}_{4}{ }^{+}$transporter gene also displays a negative correlation with glutamine concentration in the tissues (Rawat et al. 1999). Despite circumstantial evidence clearly supports the view that amino acids (or at least some of them) are repressors of root $\mathrm{NO}_{3}{ }^{-}$and $\mathrm{NH}_{4}{ }^{+}$uptake systems, this hypothesis still awaits final confirmation because the underlying mechanisms remain obscure at the molecular level. Furthermore, not all data are consistent with a negative correlation between downward phloem transport of amino acids and $\mathrm{NO}_{3}{ }^{-}$uptake rate in the roots (Tillard et al. 1998; Lainé et al. 1995). Therefore, alternative hypotheses may also be considered. For instance, systemic signalling of $\mathrm{P}$ or $\mathrm{S}$ status of the plant has unexpectedly been shown to rely on shootto-root transport of miRNAs (Chiou et al. 2006; Pant et al. 2008; Liu et al. 2009; Kawashima et al. 2009). It is not known yet whether long-distance transport of specific miRs is also associated with changes in $\mathrm{N}$ status of the whole plant, or not. However, the occurrence of Nregulated miRs has been recently reported (Pant et al. 2009; Gifford et al. 2008; Vidal et al. 2010; Zhao et al. 2011), opening new perspectives for the search of $\mathrm{N}$ related signal molecules.

Finally, phytohormones and more precisely cytokinins (CKs) have been proposed to coordinate demand and acquisition of N (Kiba et al. 2011). In A.thaliana, a positive correlation between plant cytokinin contents and nitrate concentration in the growth medium as also been reported implying that $\mathrm{CKs}$ are also a $\mathrm{N}$ status signal (Kiba et al. 2011). At the molecular level, early steps of cytokinins biosynthesis is mediated by genes encoding adenosine phosphate-isopentenyltransferase (IPT genes). In $A$. thaliana IPT is encoded by seven genes and among them, the $\mathrm{NO}_{3}{ }^{-}$inducible IPT3 plays a crucial role (Takei et al. 2004). Given that AtIPT3 is expressed in phloem, it is likely that CKs synthesized by AtIPT3 in shoots function as a shootto-root long-distance signal of shoot $\mathrm{NO}_{3}{ }^{-}$availability (Kiba et al. 2011). In line with these results, it was found from both microarray analysis (Brenner et al. 2005) and quantitative PCR (Kiba et al. 2011) that CKs repress high-affinity root $\mathrm{NO}_{3}{ }^{-}$transporter genes in A.thaliana strengthening the hypothesis that CKs act as a $\mathrm{N}$ satiety signal to inhibit $\mathrm{NO}_{3}{ }^{-}$uptake in the root (Fig. 4). Recently, based on split root experiments, Ruffel et al. (2011) confirmed that CKs plays a major role in the root-shoot-root signalling. Interestingly, it has been reported that CKs negatively regulate other nutrient acquisition-related genes in $A$. thaliana, such as high-affinity phosphate transporter genes, high-affinity sulphate transporter genes or iron deprivation inducible genes. However, the underlying mechanisms coordinating the wide range of CKdependent morphological and physiological response is not yet known.

One intriguing question related to the systemic regulation of $\mathrm{N}$ intake into the plant is to know whether the signalling pathways are common for the acquisition of the various $\mathrm{N}$ sources $\left(\mathrm{NO}_{3}{ }^{-}, \mathrm{NH}_{4}{ }^{+}\right.$, urea...). Although it may appear likely that some kind of common mechanism should be involved in the integrated control of root $\mathrm{N}$ uptake, whatever the $\mathrm{N}$ form, evidence for this is still lacking. Rather, several studies pointed out that the mechanisms ensuring the feedback repression of NTR2 and AMT1 transporter genes are different (Gansel et al. 2001; Krouk et al. 2006; Widiez et al. 2011). For instance, Gansel et al. (2001) proposed that $\mathrm{NH}_{4}{ }^{+}$uptake was predominantly regulated by the local $\mathrm{N}$ status of the roots rather than by the $\mathrm{N}$ status of the whole plant. Furthermore, the overall transcriptome responses to $\mathrm{N}$ deficiency or $\mathrm{N}$ treatments are predominantly specific of the $\mathrm{N}$ form supplied to the plant (Ruffel et al. 2008; Merigout et al. 2008). Therefore, it is not known how a plant under mixed $\mathrm{N}$ nutrition can coordinate concurrent uptake of different $\mathrm{N}$ sources to tune its overall $\mathrm{N}$ acquisition to its $\mathrm{N}$ demand for growth.

Besides organic $\mathrm{N}$ metabolites, there are indications that $\mathrm{NH}_{4}{ }^{+}$itself may also act as a repressor of root $\mathrm{N}$ uptake systems. Indeed, the use of methionine sulfoximine (MSX), a potent inhibitor of glutamine synthetase that ensures primary assimilation of $\mathrm{NH}_{4}{ }^{+}$ into glutamine, failed to alleviate repression of NRT2.1 expression by high $\mathrm{N}$ supply in $A$. thaliana (Zhuo et al. 
Fig. 4 Schematic representation of the action of phytohormones in the $\mathrm{NO}_{3}{ }^{-}$ regulation of root and shoot growth, and of $\mathrm{NO}_{3}{ }^{-}$uptake in Arabidopsis thaliana.

Brown and green boxes schematise respectively root system and shoots. Molecular players identified are listed in the white box. Green, red and black lines indicate positive, negative and complex effects, respectively. Plain and dashed lines represent known or putative functional links. Question marks represent unconfirmed results

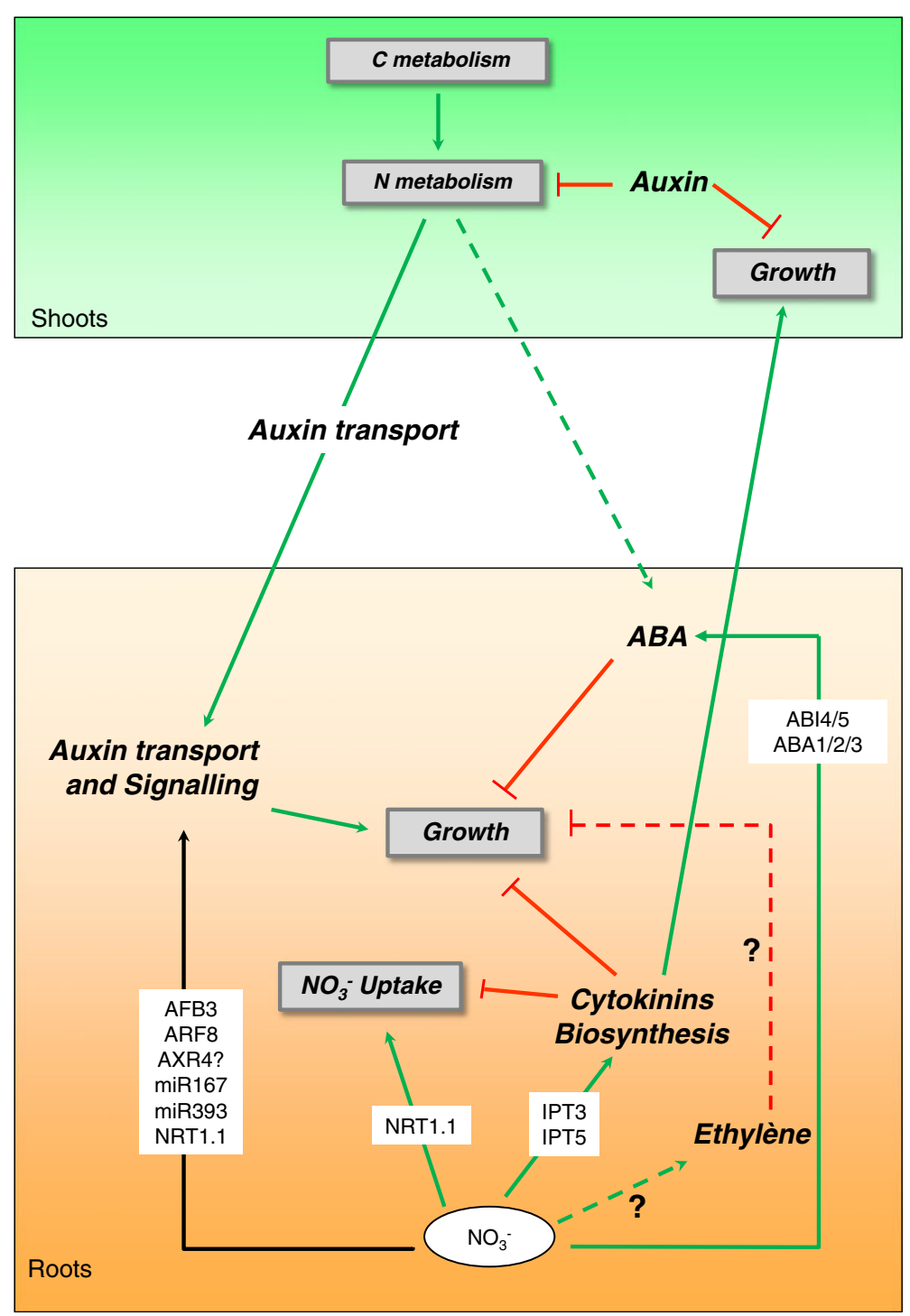

1999). Finally, although induction appears to be a prominent response of $\mathrm{NO}_{3}{ }^{-}$transporter genes to $\mathrm{NO}_{3}{ }^{-}$, some are at the opposite strongly repressed by $\mathrm{NO}_{3}^{-}$supply (e.g., NRT2.5 of $A$. thaliana, Okamoto et al. 2003), or surprisingly subject to a dual regulation (induction/repression) by $\mathrm{NO}_{3}{ }^{-}$, like NRT2.1 of A. thaliana (Fig. 2). Indeed, despite NRT2.1 expression is upregulated by shortterm $\mathrm{NO}_{3}{ }^{-}$supply (see above), it is also strongly downregulated after provision of high $\mathrm{NO}_{3}{ }^{-}$concentration for several days (Muños et al. 2004; Krouk et al. 2006). Such a time course, i.e., initial induction by $\mathrm{NO}_{3}{ }^{-}$followed by subsequent repression was also reported for root $\mathrm{NO}_{3}{ }^{-}$uptake in
NR-deficient barley plants, supporting the hypothesis that $\mathrm{NO}_{3}{ }^{-}$per se is the signal responsible for both phases of the response (King et al. 1993). Interestingly, NRT1.1 that triggers NRT2.1 induction by $\mathrm{NO}_{3}^{-}$is also required for its downregulation by long-term high $\mathrm{NO}_{3}{ }^{-}$supply (Fig. 3, Muños et al. 2004; Krouk et al. 2006). Thus, unlike wildtype plants, nrt1.1 mutants keep a high level of both NRT2.1 mRNA accumulation and $\mathrm{NO}_{3}{ }^{-}$HATS activity under ample $\mathrm{NO}_{3}{ }^{-}$provision. A surprising observation is that NRT2.1 overexpression in nrt1.1 mutants is also found in plants fed with high concentrations of both $\mathrm{NO}_{3}{ }^{-}$and $\mathrm{NH}_{4}{ }^{+}$(Muños et al. 2004; Krouk et al. 2006). This suggests that NRT1.1 might 
also participate in the feedback downregulation of NRT2.1 by reduced N metabolites, or that NRT2.1 is repressed only when both downregulatory mechanisms, by $\mathrm{NO}_{3}{ }^{-}$and reduced $\mathrm{N}$ metabolites respectively, are active. There are two findings supporting the latter hypothesis. First, unlike feedback regulation by $\mathrm{N}$ status of the plant, NRT1.1-dependent repression of NRT2.1 by high $\mathrm{NO}_{3}{ }^{-}$is a local regulation, only active in the roots that are in contact with high $\mathrm{NO}_{3}{ }^{-}$concentration (Krouk et al. 2006). Second, repression of NRT2.1 expression by high $\mathrm{NH}_{4} \mathrm{NO}_{3}$ supply (e.g., $10 \mathrm{mM}$ ) is gradually alleviated when $\mathrm{NO}_{3}{ }^{-}$concentration is decreased to a low level (e.g., $<0.5 \mathrm{mM}$ ), while $\mathrm{NH}_{4}{ }^{+}$concentration remains at $10 \mathrm{mM}$ (Krouk et al. 2006). The mechanism by which NRT1.1 represses NRT2.1 expression in presence of high $\mathrm{NO}_{3}{ }^{-}$concentration is unknown. However, Rubin et al. (2009) identified three transcription factor genes ( $L B D 37 / 38 / 39$ ) that are strongly induced by $\mathrm{NO}_{3}^{-}$, and act as repressors of NRT2.1 transcription (Fig. 3). Although no direct connection has been made to date between NRT1.1 and regulation of $L B D 37 / 38 / 39$, it will certainly be worth investigating whether NRT1.1-dependent repression of NRT2.1 requires one or several of these transcription factors.

\section{Post-transcriptional regulation of root $\mathrm{N}$ transporters}

In addition to the various mechanisms detailed above that act at the gene expression level, increasing evidence indicates that post-transcriptional regulation of root $\mathrm{N}$ transporters also plays a key role in the control of the uptake function by the roots. However, studies on this point are scarce and detailed information is only available for NRT1.1 and NRT2.1 $\mathrm{NO}_{3}{ }^{-}$transporters, and AMT1 $\mathrm{NH}_{4}{ }^{+}$transporters of $A$. thaliana.

As mentioned previously, NRT1.1 can be phosphorylated at the T101 residue, and experiments in both Xenopus oocytes and plants have suggested that the phosphorylated form is a high-affinity transporter, whereas the non-phosphorylated form is a low-affinity transporter (Liu and Tsay 2003; Ho et al. 2009). Interestingly, phosphorylation of NRT1.1 is promoted by low $\mathrm{NO}_{3}{ }^{-}$availability (Liu and Tsay 2003; Ho et al. 2009), illustrating a mean by which functional characteristics of a transporter are modulated to improve transport efficiency as a function of the actual availability of its substrate in the external medium.
The occurrence of post-transcriptional regulation of AMT1.1 was shown by the fact that its ectopic expression in both tobacco and $A$. thaliana transgenic plants failed to prevent changes in its transcript accumulation in response to $\mathrm{N}$ starvation, indicating $\mathrm{N}$-dependent regulation of AMT1.1 mRNA stability (Yuan et al. 2007). However, the best characterized mechanism for posttranscriptional regulation of AMT1 transporters is the so-called allosteric feedback inhibition that has recently been identified in A. thaliana (Loqué et al. 2007, Neuhauser et al. 2007). The AMT1.1 transport system is a trimer that can be shut off when one or several subunits are phosphorylated on the T460 residue (Lanquar et al. 2009). This phosphorylation leads to a conformational modification of the cytosolic $\mathrm{C}$ terminus domain that trans-inhibits the other subunits. It is specifically triggered by external $\mathrm{NH}_{4}^{+}$in a time and concentration manner, thus defining a local autoregulatory mechanism restricting uptake.

Little is known about posttranscriptional regulations of NRT2 transporters. Nevertheless, the importance of such a regulation has been supported by data obtained in tobacco (Fraisier et al. 2000), barley (Ishikawa et al. 2009) and A. thaliana (Wirth et al. 2007; Laugier et al. 2012). In the later species, ectopic expression of NRT2.1 actually resulted in a high and almost constant mRNA level in the roots, which did not prevent downregulation of $\mathrm{NO}_{3}{ }^{-}$HATS activity by high $\mathrm{N}$ supply. Depending on the conditions, downregulation of the HATS was associated with decreased levels of both NRT2.1 and NAR2.1 proteins abundance in membranes, or not (Laugier et al. 2012). This pinpoints the occurrence of multiple levels of $\mathrm{NO}_{3}{ }^{-}$HATS regulation, including posttranslational control of NRT2.1/NAR2.1 activity. Interestingly, NRT2.1 has recently been shown to be phosphorylated in response to $\mathrm{NO}_{3}{ }^{-}$supply (Engelsberger and Schulze 2012). However, the functional significance of this posttranslational modification remains to be determined.

\section{Regulation of root system architecture}

Size and architecture of the root system are major factors of nutrient acquisition efficiency because they determine the total volume of soil explored by the plant, and the total surface of exchange between roots and soil solution. Accordingly, many nutrients have a dramatic impact on root growth and development, and the resulting changes in root system architecture 
(RSA) generally play an important role in the plant adaptation to fluctuations of external nutrient availability. RSA of many species is strongly dependent on both external $\mathrm{N}$ availability and internal $\mathrm{N}$ status of the plant. RSA modifications have been reported to be particularly important in response to nutrients with low mobility in soil, such as $\mathrm{Pi}$ or $\mathrm{NH}_{4}{ }^{+}$. However, $\mathrm{NO}_{3}{ }^{-}$is also well known to markedly affect root development and growth, despite its high mobility (Zhang and Forde 2000; Gojon et al. 2009). This might reflect a crucial role of RSA for competing with other plants and soil microorganisms even for nutrients that can move almost freely in the soil. Interestingly, in species with a pivotal root system, $\mathrm{N}$ availability strongly modulates root branching, whereas it has a limited impact on primary root growth (Zhang and Forde 2000, Linkor et al. 2002; Lima et al. 2010; Chapman et al. 2011). Besides this general trend, defining a typical RSA phenotypic response to changes in $\mathrm{N}$ availability is almost impossible, as it is highly depending of the morphology of the root system, the species and the other abiotic environmental conditions (ie water availability, $\mathrm{pH}$, other nutrients...). However two major aspects of response appear to be common to many species: (i) a systemic repression of lateral root growth by high $\mathrm{N}$ status, and (ii) a local stimulation of lateral root growth by exogenous $\mathrm{NO}_{3}{ }^{-}$or $\mathrm{NH}_{4}{ }^{+}$supply.

Repression of root growth by high N status of the plant

High $\mathrm{N}$ supply represses root growth in many species. In A. thaliana, $\mathrm{NO}_{3}{ }^{-}$concentration over $10 \mathrm{mM}$ inhibits lateral root (LR) development, by preventing meristem activation in newly emerged primordia (Fig. 5). This leads to an accumulation of short LRs blocked just after emergence from the primary root (Zhang et al. 1999). This effect is reversible as transferring seedlings to $\mathrm{NO}_{3}{ }^{-}$-limiting media results in a release of LR inhibition within $24 \mathrm{~h}$. In maize, high $\mathrm{NO}_{3}{ }^{-}$availability $(5 \mathrm{mM})$ strongly inhibits not only LR elongation but also growth of primary, seminal and crown roots (Chun et al. 2005, Tian et al. 2008). In $A$. thaliana, the repression of LR growth by high $\mathrm{NO}_{3}{ }^{-}$is systemic because it can be observed in split root plants where high $\mathrm{NO}_{3}{ }^{-}$supply on one side of the root system is able to repress LR elongation in the other portion of the root system fed with a low $\mathrm{NO}_{3}{ }^{-}$medium (Zhang et al. 1999). The nature of the signal responsible for the repression is unclear. A high shoot $\mathrm{NO}_{3}{ }^{-}$status seems important for the inhibitory response as this effect is enhanced in a nitrate reductase deficient mutant, suggesting that systemic signalling of $\mathrm{NO}_{3}{ }^{-}$accumulation in the shoot causes LR inhibition (Zhang et al. 1999). However, $\mathrm{NH}_{4}{ }^{+}$and organic $\mathrm{N}$ molecules such as glutamine also trigger inhibition of LR growth. Gifford et al. (2008) reported that glutamine was the predominant signal regulating repression of LR emergence. Indeed, they observed that, in $A$. thaliana, the LR growth inhibition induced by high $\mathrm{NO}_{3}{ }^{-}$concentration can be alleviated by MSX, and restored when glutamine is added in the culture medium. Altogether, these data might suggest that there are at least two different signals regulating different stages of LR growth, with the "glutamine-dependent signalling pathway" controlling LR initiation/pre-emergence vs. the " $\mathrm{NO}_{3}{ }^{-}$-dependent signalling pathway" controlling LR elongation. Furthermore, several lines of evidence suggest the implication of phytohormones as long distance signals involved in the $\mathrm{N}$ regulation of root development and growth (Fig. 4). Forde (2002) hypothesized that $\mathrm{NO}_{3}{ }^{-}$ accumulation in shoots may inhibit the flux of auxin down to the roots, leading to a failure of the lateral roots to pass an auxin-requiring checkpoint in LR development. In agreement with this hypothesis, it was measured that transferring seedlings from high to low $\mathrm{NO}_{3}{ }^{-}$increases Indol Acetic Acid (IAA) root content by $50 \%$ within $24 \mathrm{~h}$ (Walch-Liu et al. 2005), and that soybean seedlings grown on $1 \mathrm{mM} \mathrm{NO}_{3}{ }^{-}$ have four-fold higher IAA concentration than plants grown on $8 \mathrm{mM} \mathrm{NO}_{3}^{-}$(Caba et al. 2000). Furthermore, inhibition of maize root growth by high $\mathrm{NO}_{3}{ }^{-}$levels has been closely related to a reduction level of IAA in roots, especially in the section close to the root tip where IAA content can be reduced up to $80 \%$ (Tian et al. 2008). In agreement, these authors found that exogenous IAA and NAA (a synthetic analogue of auxin) are able to restore growth in high $\mathrm{NO}_{3}{ }^{-}$conditions. There is also evidence that a second plant hormone, abscissic acid (ABA) may be involved in the systemic regulation of root growth. Three ABAinsensitive mutants (abi4.1, abi4.2 and abi5.1) and four ABA synthesis mutants (aba1.1, aba2.3, aba2.4 and $a b a 3.2$ ) display a significantly reduced inhibition of LR growth under abundant $\mathrm{NO}_{3}{ }^{-}$supply (Signora et al. 2001). Furthermore, LR ABA insensitive (labi) mutants, that can still produce LRs in the presence of 
Fig. 5 Schematic representation of the effects of $\mathrm{NO}_{3}{ }^{-}$on lateral root initiation and growth in Arabidopsis thaliana. The central part of ferent developmental stages of lateral roots from initiation (chart most to the left) to elongating lateral roots (chart most to the right). The upper part represents the effect of $\mathrm{NO}_{3}{ }^{-}$whereas the lower represent the NRT1-1 dependent responses to low $\mathrm{NO}_{3}{ }^{-}$concentration (light blue) or local nitrate supply (dark blue). Green Yellow and Pink pannels schematise respectively Auxin, ABA signalling pathways. Black boxes are the different phytohormones identified. Purple dot, blue arrows and brown arrowheads represent auxin accumulation, auxin flux toward primary root tissues and lateral roots elongation rate, respectively. Green and red lines indicate positive and negative effects, respectively the figure represents the dif-

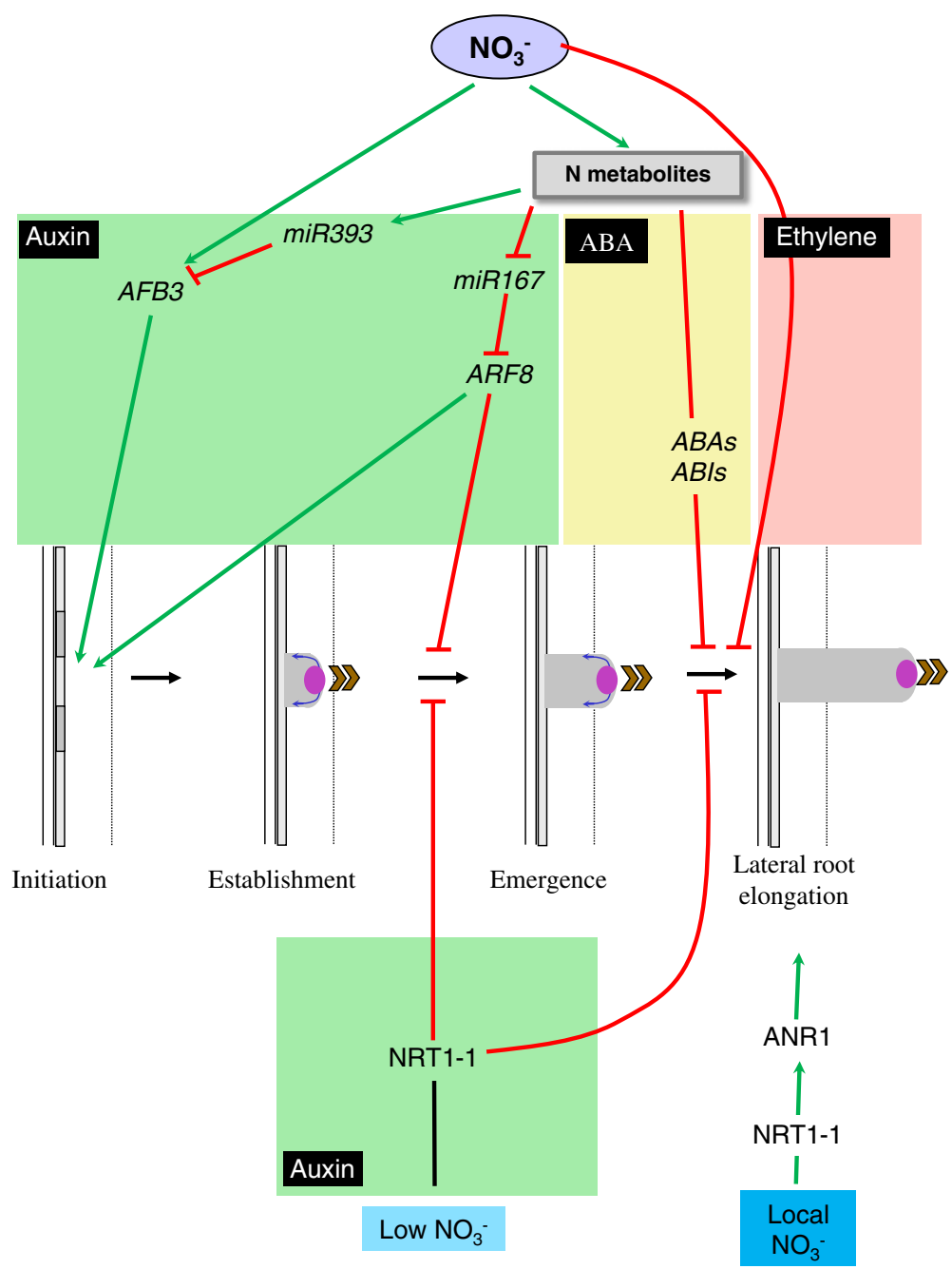

ABA, are also less sensitive to high $\mathrm{NO}_{3}{ }^{-}$(Zhang et al. 2007), and exogenous ABA supply mimics the $\mathrm{NO}_{3}{ }^{-}$-induced inhibition of LR elongation (De Smet et al. 2003) although this seems to be a little later than the arrest observed in the presence of high $\mathrm{NO}_{3}{ }^{-}$. In addition, these groups demonstrated that exogenous auxin supply does not overcome the ABA-induced arrest, suggesting that $\mathrm{ABA}$ and auxin are acting through independent pathways. Cytokinins were also proposed to participate to root growth limitation in maize plants supplied with high $\mathrm{NO}_{3}{ }^{-}$(Tian et al. 2005). Recently, ethylene was shown to be involved in high $\mathrm{NO}_{3}{ }^{-}$LR growth limitation in A. thaliana. Indeed, transferring plants from low to high $\mathrm{NO}_{3}{ }^{-}$ induces a rapid burst of ethylene production, leading to root growth limitation. In agreement, this root growth inhibition is suppressed in ethylene signalling mutants or when ethylene synthesis antagonists are present in the culture medium (Tian et al. 2009). However the precise role of both cytokinins and ethylene remain elusive.

Stimulation of lateral root growth by $\mathrm{NO}_{3}{ }^{-}$and $\mathrm{NH}_{4}{ }^{+}$

Local $\mathrm{N}$ availability also directly affects root growth. The most documented response concerns $\mathrm{NO}_{3}{ }^{-}$but several reports also pinpoint a similar effect of $\mathrm{NH}_{4}{ }^{+}$ whereas very little is known about local organic $\mathrm{N}$ supply. A major illustration of the effect of local $\mathrm{N}$ concentration which has been well documented in the literature for many years is the so-called "root proliferation response", i.e., the ability of plants to proliferate roots preferentially in nutrient-rich patches (Nobbe F. 1862). Drew (1975), through a detailed RSA 
analysisdemonstrated that a nutrient rich 'patch' could elicit a localized increase in LR initiation and elongation in barley. However, the importance of root proliferation for $\mathrm{N}$ capture from patches appeared a paradox because, although root proliferation within N-rich patches could easily be demonstrated, the benefit in terms of $\mathrm{N}$ capture from the patch could not (van Vuuren et al. 1996; Hodge et al. 1998; Fransen et al. 1998). These three studies all used different plant species but in all cases plants were grown as individuals. When considered within the context of interplant competition, it has been demonstrated that when plants are competing for a common patch of organic $\mathrm{N}$, root proliferation does make sense: the species which proliferated the most captured the most $\mathrm{N}$ (Hodge et al. 1999, 2000; Robinson et al. 1999).

In contrast with its systemic inhibitory effect on LR growth, $\mathrm{NO}_{3}{ }^{-}$locally promotes initiation and/or elongation of LRs (Fig. 5). This adaptive response was extensively studied in A. thaliana, in which Zhang and Forde (1998) demonstrated that a localised patch of $\mathrm{NO}_{3}{ }^{-}$in a split agar plate elicited a preferential LR growth in the region of the patch. This resulted from the combination of a strong increase in LR elongation and a marked stimulation of LR primordia emergence in the $\mathrm{NO}_{3}{ }^{-}$-enriched region (Zhang and Forde 1998; Zhang et al. 1999; Linkohr et al. 2002; Remans et al. 2006; Krouk et al. 2010b). $\mathrm{NO}_{3}{ }^{-}$rather than its downstream metabolites appears to be the signal for the stimulation as a mutant in nitrate reductase shows the wildtype response (Zhang and Forde 1998). Besides this positive effect of local $\mathrm{NO}_{3}{ }^{-}$concentration, Linkohr et al. (2002) found that within the same plant, the unequal distribution of LRs between $\mathrm{NO}_{3}{ }^{-}$-rich and $\mathrm{NO}_{3}{ }^{-}$-poor patches is also due to repression of lateral root elongation in the $\mathrm{NO}_{3}{ }^{-}$-poor patch, which was recently confirmed by Krouk et al. (2010b). Finally, if the localized $\mathrm{NO}_{3}{ }^{-}$supply is made on a too restricted portion of the total root system, the consequent $\mathrm{N}$ limitation alleviates the systemic repression by high $\mathrm{N}$ status, further amplifying the local proliferation response. Several molecular components of the signalling pathway responsible for the local positive effect of $\mathrm{NO}_{3}{ }^{-}$have now been identified in Arabidopsis (Fig. 5). The ANR1 MADS box putative transcription factor was characterized as a critical component for the local root elongation stimulation as the response is drastically reduced in ANRI antisens or co-suppressed plants (Zhang and Forde 1998) and is stimulated in ANR1 inducible transgenic lines (Gan et al. 2012). Zhang and Forde (1998) also speculate that a downstream target of local $\mathrm{NO}_{3}{ }^{-}$response might be $A X R 4$ gene as they reported that the axr4 mutant showed attenuated response to local $\mathrm{NO}_{3}{ }^{-}$supply (Zhang et al. 1999). However, Linkohr et al. (2002) found in similar experiments that the axr4 response is similar to WT. More recently, the Arabidopsis $\mathrm{NO}_{3}{ }^{-}$ transporter NRT1.1 was reported to also play a crucial role in the signalling process (Fig. 5), possibly as an upstream membrane $\mathrm{NO}_{3}{ }^{-}$sensor responsible for the initial perception of the external $\mathrm{NO}_{3}{ }^{-}$concentration that triggers the whole regulatory pathway (Remans et al. 2006). Indeed, these authors found that nrt1.1 mutants display a strongly reduced response to a localised $\mathrm{NO}_{3}{ }^{-}$supply, similarly to ANR1 downregulated lines. Interestingly, the reduced responsiveness was not due to a decrease in $\mathrm{NO}_{3}{ }^{-}$acquisition as the specific uptake activity was not reduced (Remans et al. 2006). More importantly, chll mutants have a markedly reduced abundance of ANR1 transcript, suggesting that NRT1.1 may act upstream ANR1. These data further support the hypothesis that NRT1.1 acts as a $\mathrm{NO}_{3}{ }^{-}$transceptor (Gojon et al. 2011, see above). Interestingly, unlike for the other NRT1.1-dependent signalling pathways, a precise molecular mechanism has been proposed to account for the role of NRT1.1 in the $\mathrm{NO}_{3}{ }^{-}$regulation of development of the LR primordia (Krouk et al. 2010b). Indeed, the $\mathrm{NO}_{3}{ }^{-}$-induced stimulation of LR emergence and growth is associated with an increased accumulation of auxin at the apex of primordia or of newly emerged LRs. This auxin maximum is mandatory for further development and growth of these organs (Benkova et al. 2003). NRT1.1 is required for the local increase of auxin accumulation in response to $\mathrm{NO}_{3}{ }^{-}$, not because it promotes this accumulation in presence of $\mathrm{NO}_{3}{ }^{-}$, but because it prevents it in the absence of $\mathrm{NO}_{3}{ }^{-}$(Krouk et al. 2010b). Accordingly, primordia and newly emerged lateral roots of chll mutants display a constitutively high level of auxin, which results in a constitutive high rate of primordia emergence and growth, regardless of the external $\mathrm{NO}_{3}{ }^{-}$concentration (Krouk et al. 2010b). The reason why NRT1.1 controls the $\mathrm{NO}_{3}{ }^{-}$-induced accumulation of auxin in lateral roots is that this protein is able to transport auxin in $\mathrm{NO}_{3}{ }^{-}$-dependent manner, as shown in heterologous expression experiments in Xenopus oocytes, S. cerevisiae or BY2 cells (Krouk et al. 2010b). 
Altogether, these data led to the proposal of a model postulating that in the absence, or at low external availability, of $\mathrm{NO}_{3}{ }^{-}$, NRT1.1 behaves as an auxin transport facilitator that contributes to remobilize the hormone out of the lateral root toward the parent root, therefore repressing emergence and growth of this organ. At high $\mathrm{NO}_{3}{ }^{-}$concentration, auxin transport facilitation by NRT1.1 is inhibited, and auxin accumulates at the apex of the lateral root, which in turn promotes emergence and growth (Krouk et al. 2010b). Such mechanism has only been identified in A. thaliana. However, recent findings suggest that a protein belonging to the NRT1 (PTR) family, encoded by the M. truncatula LATD gene regulates the legume root system architecture. Indeed, $L A T D$ is expressed in the root meristem and elongation zone (Yendrek et al. 2010), and is required for the maintenance of primary and LR growth and of symbiotic nodule meristem. In addition, latd mutants are insensitive to the inhibition of the primary root growth by $\mathrm{NO}_{3}{ }^{-}$(Yendrek et al. 2010). Besides this, another member of the M. truncatula PTR family, MtNRT1.3, has been characterised (Morere-Le Paven et al. 2011). Like the A.thaliana NRT1.1, this transporter behaves as a dual affinity $\mathrm{NO}_{3}{ }^{-}$transporter when expressed in Xenopus oocytes. Interestingly, it has been associated with a QTL of root development, although the demonstration that MtNRT1.3 is the QTL still remains to be done. Taken together, these results suggests that the $\mathrm{NO}_{3}{ }^{-}$sensing and signalling function of PTR members is not only restricted to $A$. thaliana but may also be observed in other species.

An additional evidence indicating that auxin signalling is involved in the local stimulation of LR growth by $\mathrm{NO}_{3}{ }^{-}$is the recent finding that the gene encoding the AFB3 auxin receptor is strongly induced by $\mathrm{NO}_{3}{ }^{-}$, and that stimulation of LR primordia initiation by $\mathrm{NO}_{3}{ }^{-}$is markedly reduced in an $a f b 3$ mutant (Vidal et al. 2010).

The hypothesis that, in addition to $\mathrm{NO}_{3}{ }^{-}$, external $\mathrm{NH}_{4}^{+}$could also be sensed specifically by the roots, and could trigger adaptive RSA responses has been a matter of debate. Heterogeneous $\mathrm{NH}_{4}{ }^{+}$ supply to sand-grown barley plants (Drew 1975) or to Cedrus atlantica (Boukcim et al. 2006) also resulted in a localized proliferation of LRs. Splitroot experiments in $A$. thaliana indicated that the localized stimulation of LR elongation induced by $\mathrm{NO}_{3}{ }^{-}$could not be mimicked by $\mathrm{NH}_{4}{ }^{+}$(Zhang et al. 1999; Remans et al. 2006). Nevertheless, recent reports provide convincing evidence that $\mathrm{NH}_{4}{ }^{+}$present in the external medium is indeed perceived as a signal molecule by the roots, possibly via AMT1 transporters (see above and Lanquar et al. 2009), and can regulate LR development. Indeed, a detailed reconsideration of the action of $\mathrm{NH}_{4}^{+}$on RSA in $A$. thaliana unravelled specific effects different from those of $\mathrm{NO}_{3}{ }^{-}$. Unlike $\mathrm{NO}_{3}{ }^{-}$ that predominantly promotes LR emergence and elongation, localized $\mathrm{NH}_{4}^{+}$supply was found to mainly increase initiation of second and third order LR primordia, leading to a highly branched root system, while further elongation of pre-emerged root initials was strongly reduced, resulting in a much more "bushy" architecture than with $\mathrm{NO}_{3}{ }^{-}$(Lima et al. 2010). Taken together, these results suggest that $\mathrm{NO}_{3}{ }^{-}$and $\mathrm{NH}_{4}{ }^{+}$have complementary actions on RSA, that were shown to be at least partly additive when $\mathrm{NH}_{4}{ }^{+}$and $\mathrm{NO}_{3}{ }^{-}$are supplied together (Lima et al. 2010). Interestingly, the RSA responses to localized $\mathrm{NH}_{4}{ }^{+}$supply cannot be explained by a nutritional effect alone and required the presence of a functional AMT1.3 transporter (Lima et al. 2010), thus making an interesting parallel with the NRT1.1-dependent lateral root proliferation in response to localized $\mathrm{NO}_{3}{ }^{-}$supply.

Very little is known about the RSA response to local organic $\mathrm{N}$ application. However, it has been reported that L-glutamate is able to inhibit primary root growth even at low concentration (0.05$0.5 \mathrm{mM}$ ) (Filleur et al. 2005 and Walch-Liu et al. 2006). This response was highly specific for Lglutamate, as similar concentrations of related amino acids or of D-glutamate had no effect. The effects on RSA are complex because although inhibition of primary root growth was detectable within $24 \mathrm{~h}$ of transfer to L-glutamate, LRs only acquired sensitivity after some time (once they reach an average length of 5$7 \mathrm{~mm}$ ). Finally, L-glutamate promoted an outgrowth of LRs close to the root tip. The net result is a bushy and more branched root system similar to the phenotype seen when $A$. thaliana seedlings were grown on a limiting supply of P (Williamson et al. 2001, Lopez Bucio et al. 2002; Svistoonoff et al. 2007). This response is not only observed in A. thaliana but also in Arabidospis-related species, tomato and poppy (Walch-Liu et al. 2005). Interestingly the inhibitory effect of L-Glutamate is alleviated by $\mathrm{NO}_{3}{ }^{-}$, through the involvement of a NRT1.1-dependent signaling pathway (Walch-Liu and Forde 2008). 


\section{Slowing down of shoot growth}

Most often, it is assumed that the detrimental effects of sub-optimal $\mathrm{N}$ availability on plant biomass production and yield are due to metabolic limitations in the various organs, resulting from inadequate $\mathrm{N}$ acquisition by the root system. In other words, the plant does not reach its full growth potential because internal $\mathrm{N}$ is not available enough to ensure synthesis of biomolecules at the level required to sustain unlimited growth. This is particularly crucial in the shoot, because photosynthesis is a high Ndemanding process as Rubisco alone can account for up to $20-40 \%$ of total $\mathrm{N}$ in the leaves (Evans 1989). However, there is now mounting evidence that slowing down of shoot growth under situations of $\mathrm{N}$ limitation is not only a consequence of internal $\mathrm{N}$ deficiency, but also a fast adaptive response of the plant to prevent internal $\mathrm{N}$ deficiency. Indeed, numerous studies have shown that reduction of leaf expansion rate occurs very fast in response to $\mathrm{N}$ limitation or starvation, and precedes any measurable symptom of organic $\mathrm{N}$ deficiency (Chapin et al. 1988; Chapin 1991; Palmer et al. 1996; Rahayu et al. 2005). Furthermore, it is known for long that N-limited plants accumulate large amounts of carbohydrates, indicating that decay of photosynthesis is a consequence rather than a cause of growth rate restriction (Radin and Eidenbock 1986; Rufty et al. 1988; Chapin 1991). The concept that fast slowing down of growth constitutes an adaptive response to $\mathrm{N}$ limitation is not new, as it has been proposed to be part of a centralized system of physiological responses to nutrient or water stresses (Chapin 1991). The role of this centralized system is to improve survivorship under unfavourable conditions, by restraining growth and thus preventing metabolic disorders associated with restricted nutrient acquisition. Most probably, fast slowing down of shoot growth also contributes to a modified allocation of assimilates in favour of the root system (less demanding for $\mathrm{N}$ ), leading to the well kown decrease of the shoot to root biomass ratio in response to $\mathrm{N}$ limitation (Hermans et al. 2006). Thus, concurrently with regulatory mechanisms aiming at maintaining the $\mathrm{N}$ offer to the various organs through improved $\mathrm{N}$ acquisition efficiency (see above sections), it clearly appears that plants ensure $\mathrm{N}$ homeostasis by also reducing the $\mathrm{N}$ demand through reduced growth of the above ground organs.

Compelling evidence has accumulated supporting the hypothesis that the regulatory mechanisms quickly modulating shoot growth as a function of $\mathrm{N}$ availability also involve a tight connection between $\mathrm{N}$ and hormone signalling pathways, as it is the case with the $\mathrm{N}$ regulation of root system architecture (Chapin 1991; Sakakibara et al. 2006; Rubio et al. 2009; Vidal et al. 2010; Krouk et al. 2011). As conceptualized by Chapin (1991), changes in external $\mathrm{N}$ availability may trigger fast responses of shoot growth through modified absissic acid (ABA) and/or cytokinin (CK) levels. Interestingly, recent transcriptomic studies indeed indicate that many $\mathrm{NO}_{3}{ }^{-}$-responsive genes related to primary or energy metabolism and to photosynthesis are also regulated by ABA and/or cytokinins (Nero et al. 2009). Despite some indication that decreased $N$ supply affects ABA accumulation in shoots (Chapin 1991; Brewitz et al. 1995), correlation between leaf ABA levels and short- or long-term $\mathrm{N}$-induced changes in shoot growth was found to be relatively poor (Rahayu et al. 2005). However, the recent finding that the $A$. thaliana NRT1.2 transporter is also able to transport ABA may provide some new hypotheses on this point (Kanno et al. 2012). In contrast, the connection between $\mathrm{N}$ and $\mathrm{CK}$ signalling, and its role in the regulation of shoot growth is much better characterized (Sakakibara et al. 2006). $\mathrm{N}$ provision to the plant results in many different species in an increase in CK content of the tissues (Samuelson and Larsson 1993; Wagner and Beck 1993; Takei et al. 2001, 2004). Most importantly, this also leads to a strong stimulation of CK transport from root to shoot in the xylem (Takei et al. 2001, 2004). In $A$.thaliana, this is due to the specific induction by $\mathrm{N}$ compounds of a set of key enzymes involved in CK biosynthesis in the roots, namely IPTs and cytochrome P450 monooxygenases (CYP735A), that promote transzeatin (an highly active CK form) production and export (also as trans-zeatin riboside) into the xylem (Sakakibara et al. 2006). Among the 7 IPT genes present in the $A$. thaliana genome, IPT3 and IPT5 were found to be induced in the roots by $\mathrm{N}$ supply, with IPT3 responding specifically to $\mathrm{NO}_{3}{ }^{-}$within only $1 \mathrm{~h}$ after treatment (Miyawaki et al. 2004; Takei et al. 2004; Wang et al. 2004). Accordingly, $\mathrm{NO}_{3}{ }^{-}$-induced $\mathrm{CK}$ biosynthesis was strongly reduced in an insertion mutant of IPT3 (Takei et al. 2004). In both $A$. thaliana and maize, stimulation of CK xylem transport by $\mathrm{N}$ supply activates $\mathrm{CK}$ signalling cascades by His-Asp phospho-relay in leaves (Sakakibara et al. 1998; Taniguchi et al. 1998). Since CK promote cell division in the shoot apical meristems, this suggests that these hormones act as long-distance 
signals of $\mathrm{N}$ availability in the roots to directly and rapidly stimulate shoot growth (Fig. 4). Accordingly, changes in leaf expansion rate in response to $\mathrm{NO}_{3}{ }^{-}$in tomato (that can be recorded as fast as $4 \mathrm{~h}$ after a change in $\mathrm{NO}_{3}{ }^{-}$supply) are strongly correlated with changes in the zeatin and zeatin riboside concentrations in the xylem sap (Rahayu et al. 2005). Moreover, the observation that some of the molecular components involved in this system respond specifically to $\mathrm{NO}_{3}{ }^{-}$and not to other $\mathrm{N}$ compounds (i.e., specific induction of IPT3 by $\mathrm{NO}_{3}{ }^{-}$) likely accounts for the predominant effect of $\mathrm{NO}_{3}{ }^{-}$in stimulating shoot growth. Indeed, increase in leaf expansion rate after $\mathrm{NO}_{3}{ }^{-}$supply has been recorded both in plants previously N-starved or precultured with $\mathrm{NH}_{4}{ }^{+}$ as an $\mathrm{N}$ source (Walch-Liu et al. 2005; Rahayu et al. 2005). Thus, at least part of the growth difference observed in many plant species between $\mathrm{NO}_{3}{ }^{-}$or $\mathrm{NH}_{4}{ }^{+}$ nutrition may not be due to $\mathrm{NH}_{4}{ }^{+}$toxicity per se, but to the fact that only $\mathrm{NO}_{3}{ }^{-}$is able to fully activate the $\mathrm{CK}$ signalling cascade stimulating shoot growth. This indicates a direct link between $\mathrm{CK}$ signalling in shoots and $\mathrm{NO}_{3}{ }^{-}$sensing systems in roots that is further documented by the report that induction of ITP 3 by $\mathrm{NO}_{3}{ }^{-}$is partly dependent on the NRT1.1 $\mathrm{NO}_{3}{ }^{-}$transceptor in $A$. thaliana (Kiba et al. 2011). Although it is difficult to extrapolate from one single example (connection between NRT1.1 and CK signalling), the model that emerges from these observations is that plants are able to quickly modulate (within hours) their shoot growth as a function of their perception of nutrient availability to the roots. This certainly allows fast survival responses as soon as the environment is detected to be unfavourable for growth, and thus before any decrease in the whole plant nutrient status had occurred.

If correct, this model implies that manipulation of the nutrient sensing systems in the roots will affect the response of shoot growth to changes in nutrient availability. Interestingly, the NRT1.1 $\mathrm{NO}_{3}{ }^{-}$transceptor, which participates in the $\mathrm{NO}_{3}{ }^{-}$regulation of $\mathrm{LR}$ growth in $A$. thaliana (see above section), has recently been shown to also modulate shoot growth as a function of the $\mathrm{N}$ source (Hachiya et al. 2011). However, there is no evidence yet that a putative role of NRT1.1 in the regulation of shoot growth is due to modified root-to-shoot CK signalling. Another intriguing report in this general context is the recent paper by Rouached et al. (2011) concerning the $\mathrm{PHO} 1$ phosphate (Pi) transporter of $A$. thaliana. $\mathrm{PHO} 1$ is predominantly expressed in the root vasculature, and is believed to play a key role in the translocation of Pi to the shoot via the xylem (Poirier et al. 1991; Hamburger et al. 2002). Accordingly, null pho1 mutants grown in soil display a dramatic reduction of $\mathrm{Pi}$ export from the roots, leading in the shoot to a markedly diminished Pi content, a strong reduction of growth, and a gene expression profile typical of $\mathrm{P}$ deficiency. Unexpectedly, $\mathrm{PHOl}$ underexpressors or transformants expressing the rice $\mathrm{PHOl}$ ortholog in a phol A. thaliana mutant background, show almost complete recovery of shoot growth and suppression of transcriptome responses triggered by $\mathrm{P}$ deficiency, despite an only very partial complementation of the $\mathrm{Pi}$ export function (Pi translocation rate 2.6 to 4.2 -fold lower than in the wild type, Rouached et al. 2011). As a consequence, these lines have very low shoot Pi content, similar to that of phol mutants (i.e., 3 to 4-fold lower than the wild type). Altogether, these results indicate that the responses of the above ground organs to Pi deficiency (restricted growth and transcriptome reprogramming) can be uncoupled from low Pi content of the shoot, but require a fully functional PHO1 transporter in the roots. Although this does not demonstrates that PHO1 has an actual Pi sensing role, it will certainly be worth investigating why its genetic manipulation yields the exciting phenotype of a fully normal shoot growth with only one-third of the $\mathrm{Pi}$ content of wild type shoots.

\section{Conclusion and future prospects}

There are at least three aspects for which our understanding of the mechanisms of plant adaptation to changes in $\mathrm{N}$ availability has significantly progressed within the past years. First, the molecular structure of both $\mathrm{NO}_{3}{ }^{-}$and $\mathrm{NH}_{4}{ }^{+}$root uptake systems has been further detailed to reach an almost comprehensive knowledge. This allowed identifying the key transporters targeted by the $\mathrm{N}$ regulatory mechanisms, and responsible for the functional flexibility of root $\mathrm{N}$ acquisition. Second, major advance has been made in the elucidation of the $\mathrm{N}$ signalling pathways involved in sensing of external $\mathrm{N}$ availability. This is most obvious in the case of $\mathrm{NO}_{3}{ }^{-}$, with the mounting hypothesis that some of the membrane transporters of the NRT1 familly actually fufill a dual transport/sensing function, and act as transceptors. Finally, a strong body of evidence indicate that many adaptive developmental responses to changes in $\mathrm{N}$ availability are triggered by a direct connection between $\mathrm{N}$ and 
hormone signalling pathways. In some instances, the two later aspects strongly interact, as highlighted by the recent finding that both NRT1.1 and NRT1.2 transporters of $A$. thaliana have a dual $\mathrm{NO}_{3}{ }^{-}$/hormone substrate specificity. Yet, a lot remains to be done in this field. Concerning the structure and regulation of the root uptake systems, it remains to determine whether the conceptual model we now have in model plants such as A. thaliana (i.e., functional organisation of NRT1, NRT2, AMT1, DUR3 transporter familles) is also valid for crops, or not. Furthermore, if it appears now feasible to almost totally suppress root $\mathrm{N}$ uptake capacity of a plant by knockingdown the few relevant transporter genes, attempts to improve root $\mathrm{N}$ uptake efficiency by manipulating these transporters has been hardly successful to date. Clearly, there are either other limiting steps or levels of regulation and integration we still do not understand, and which prevent a simple genetic or biotechnological use of the key transporter genes. Deciphering the $\mathrm{N}$ sensing and signalling pathways that allow the plant to determine the amount and precise localization of the $\mathrm{N}$ resources in the soil is certainly a major priority. This is important to improve our basic knowledge of biological processes that are most propably specific to plants, but this is also important because it now appears that these sensing and signalling pathways are directly connected to the control of growth through hormone signalling. Thus, by manipulating the $\mathrm{N}$ sensing systems, one can expect improving crop yield at low $\mathrm{N}$ fertilizer input by preventing the slowing down of growth directly triggered by the perception of a suboptimal level of $\mathrm{N}$ in the soil. Another area where a significant breakthrough is needed relates to whole plant $\mathrm{N}$ signalling. Although extensively described at the physiological level, the molecular mechanisms responsible for the systemic signalling of plant $\mathrm{N}$ status remain almost totally unknown. This strongly departs from major advance made on $\mathrm{P}$ or $\mathrm{S}$ signalling, and raises questions about the relevant strategies to develop to reach this goal. Finally, the dramatic plasticity of RSA in response to $\mathrm{N}$ availability has been only recently fully acknowledged. The mechanisms responsible for it have begun to be unravelled, yielding original and exciting hypotheses. No doubt that exploiting this plasticity of root development will be an important strategy to improve N use efficiency in plants (Lynch 2007; Lynch and Brown 2012; Pages 2011). This certainly calls for major efforts toward high-throughput phenotying of RSA, in particular in the field.

\section{References}

Alvarez JM, Vidal EA, Gutiérrez RA (2012) Integration of local and systemic signaling pathways for plant $\mathrm{N}$ responses. Curr Opin Plant Biol 15:185-191

Amarasinghe BH, de Bruxelles GL, Braddon M, Onyeocha I, Forde BG, Udvardi MK (1998) Regulation of GmNRT2 expression and nitrate transport activity in roots of soybean (Glycine max). Planta 206:44-52

Barbier-Brygoo H, De Angeli A, Filleur S, Frachisse JM, Gambale F, Thomine S, Wege S (2011) Anion channels/ transporters in plants: from molecular bases to regulatory networks. Annu Rev Plant Biol 62:25-51

Benkova E, Michniewicz M, Sauer M, Teichmann T, Seifertova D, Jurgens G, Friml J (2003) Local, efflux-dependent auxin gradients as a common module for plant organ formation. Cell 115:591-602

Boukcim H, Pages L, Mousain D (2006) Local $\mathrm{NO}_{3}{ }^{-}$or $\mathrm{NH}_{4}{ }^{+}$ supply modifies the root system architecture of Cedrus atlantica seedlings grown in a split-root device. J Plant Physiol 163:1293-1304

Brenner WG, Romanov GA, Köllmer I, Bürkle L, Schmülling T (2005) Immediate-early and delayed cytokinin response genes of Arabidopsis thaliana identified by genome-wide expression profiling reveal novel cytokinin-sensitive processes and suggest cytokinin action through transcriptional cascades. Plant J 44:314-333

Brewitz E, Larsson C-M, Larsson M (1995) Influence of nitrate supply on concentrations and translocation of abscisic acid in barley (Hordeum vulgare). Phvsiol Plant 95:499-506

Burns IG (1991) Short and long term effects of a change in the spatial distribution of nitrate in the root zone on $\mathrm{N}$ uptake, growth and root development of young lettuce plants. Plant Cell Environ 14:21-23

Caba JM, Centeno ML, Fernandez B, Gresshoff PM, Ligero F (2000) Inoculation and nitrate alter phytohormone levels in soybean roots: differences between a supernodulating mutant and the wild type. Planta 211:98-104

Cai C, Wang JY, Zhu YG, Shen QR, Li B, Tong YP, Li ZS (2008) Gene structure and expression of the high-affinity nitrate transport system in rice roots. J Integr Plant Biol 50:443-451

Camanes G, Cerezo M, Primo-Millo E, Gojon A, GarciaAgustin P (2007) Ammonium transport and CitAMT1 expression are regulated by light and sucrose in Citrus plants. J Exp Bot 58:2811-2825

Camargo A, Llamas A, Schnell RA, Higuera JJ, GonzálezBallester D, Lefebvre PA, Fernández E, Galván A (2007) Nitrate signaling by the regulatory gene NIT2 in Chlamydomonas. Plant Cell 19:3491-3503

Canfield DE, Glazer AN, Falkowski PG (2010) The evolution and future of earth's nitrogen cycle. Science 330:192-196

Castaings L, Camargo A, Pocholle D, Gaudon V, Texier Y, Boutet-Mercey S, Taconnat L, Renou JP, Daniel-Vedele F, Fernandez E, Meyer C, Krapp A (2009) The nodule inception-like protein 7 modulates nitrate sensing and metabolism in Arabidopsis. Plant J 57:426-435

Cerezo M, Tillard P, Filleur S, Munos S, Daniel-Vedele F, Gojon A (2001) Major alterations of the regulation of $\operatorname{root} \mathrm{NO}_{3}{ }^{-}$ uptake are associated with the mutation of Nrt2.1 and Nrt2.2 genes in Arabidopsis. Plant Physiol 127:262-271 
Chapin FS (1991) Integrated responses of plants to stress. Bioscience 41:29-36

Chapin FS, Clarkson DT, Lenton LR, Walter CHS (1988) Effect of nitrogen stress and abscissic acid on nitrate absorption and transport in barley and tomato. Planta 173:340-351

Chapman N, Whalley WR, Lindsey K, Miller AJ (2011) Water supply and not nitrate concentration determines primary root growth in Arabidopsis. Plant Cell Environ 34:1630-1638

Chiou TJ, Aung K, Lin S, Wu CC, Chiang SF, Su CL (2006) Regulation of phosphate homeostasis by microRNA in Arabidopsis. Plant Cell 18:412-421

Chun L, Mi GH, Li JS, Chen FJ, Zhang FS (2005) Genetic analysis of maize root characteristics in response to low nitrogen stress. Plant Soil 276:369-382

Clarkson DT (1985) Factors affecting mineral nutrient acquisition by plants. Ann Rev Plant Physiol 36:77-115

Cooper HD, Clarkson DT (1989) Cycling of amino-nitrogen and other nutrients between shoots and roots in cereals- A possible mechanism integrating shoot and root in the regulation of nutrient uptake. J Exp Bot 40:753-762

Crawford NM (1995) Nitrate: nutrient and signal for plant growth. Plant Cell 7:859-868

Crawford NM, Glass ADM (1998) Molecular and physiological aspects of nitrate uptake in plants. Trends Plant Sci 3:389-395

D’Apuzzo E, Rogato A, Simon-Rosin U, El Alaoui H, Barbulova A, Betti M, Dimou M, Katinakis P, Marquez A, Marini AM, Udvardi MK, Chiurazzi M (2004) Characterization of three functional high-affinity ammonium transporters in Lotus japonicus with differential transcriptional regulation and spatial expression. Plant Physiol 134:1763-1774

Datko AH, Mudd SH (1985) Uptake of amino acids and other organic compounds by Lemna paucicostata Hegelm. 6746. Plant Physiol 77:770-778

De Kroon H, Visser EJ, Huber H, Mommer L, Hutchings MJ (2009) A modular concept of plant foraging behaviour: the interplay between local responses and systemic control. Plant Cell Environ 32:704-712

De Smet I, Signora L, Beeckman T, Inzé D, Foyer CH, Zhang H (2003) An abscisic acid-sensitive checkpoint in lateral root development of Arabidopsis. Plant J 33:543-555

Diaz RJ, Rosenberg R (2008) Spreading dead zones and consequences for marine ecosystems. Science 321:926-929

Doddema H, Telkamp GP (1979) Uptake of nitrate by mutants of Arabidopsis thaliana disturbed in uptake or reduction of nitrate. II. Kinetics. Physiol Plant 45:332-338

Drew MC (1975) Comparison of effects of a localized supply of phosphate, nitrate, ammonium and potassium on growth of seminal root system and shoot in barley. New Phytol 75:479-490

Engelsberger WR, Schulze WX (2012) Nitrate and ammonium lead to distinct global dynamic phosphorylation patterns when resupplied to nitrogen-starved Arabidopsis seedlings. Plant J 69:978-995

Evans JR (1989) Photosynthesis and nitrogen relationships in leaves of C3 plants. Oecologia 78:9-19

Feng H, Yan M, Fan X, Li B, Shen Q, Miller AJ, Xu G (2011) Spatial expression and regulation of rice high-affinity nitrate transporters by nitrogen and carbon status. J Exp Bot 62:2319-2332

Filleur S, Daniel-Vedele F (1999) Expression analysis of a highaffinity nitrate transporter isolated from Arabidopsis thaliana by differential display. Planta 207:461-469
Filleur S, Dorbe MF, Cerezo M, Orsel M, Granier F, Gojon A, Daniel-Vedele F (2001) An arabidopsis T-DNA mutant affected in $\mathrm{Nrt} 2$ genes is impaired in nitrate uptake. FEBS Lett 489:220-224

Filleur S, Walch-Liu P, Gan Y, Forde BG (2005) Nitrate and glutamate sensing by plant roots. Biochem Soc Trans 33:283-286

Forde BG (2000) Nitrate transporters in plants: structure, function and regulation. Biochim Biophys Acta 1465:219-235

Forde BG (2002) Local and long-range signalling pathways regulating plant responses to nitrate. Ann Rev Plant Biol 53:203-224

Forde BG, Clarkson DT (1999) Nitrate and ammonium nutrition of plants: physiological and molecular perspectives. Adv Bot Res 30:1-90

Fraisier V, Gojon A, Tillard P, Daniel-Vedele F (2000) Constitutive expression of a putative high-affinity nitrate transporter in Nicotiana plumbaginifolia: evidence for post-transcriptional regulation by a reduced nitrogen source. Plant J 23:489-496

Fransen B, de Kroon H, Berendse F (1998) Root morphological plasticity and nutrient acquisition of perennial grass species from habitats of different nutrient availability. Oecologia $115: 351-358$

Frommer WB, Hummel S, Riesmeier JW (1993) Expression cloning in yeast of a cDNA encoding a broad specificity amino acid permease from Arabidopsis thaliana. Proc Natl Acad Sci USA 90:5944-5948

Galloway JN, Aber JD, Erisman JW, Seitzinger SP, Howarth RW, Cowling EB, Cosby BJ (2003) The nitrogen cascade. BioScience 53:341-356

Galloway JN, Townsend AR, Erisman JW, Bekunda M, Cai Z, Freney JR, Martinelli LA, Seitzinger SP, Sutton MA (2008) Transformation of the nitrogen cycle: recent trends, questions, and potential solutions. Science 320(5878):889-892

Gan Y, Bernreiter A, Filleur S, Abram B, Forde BG (2012) Overexpressing the ANR1 MADS-box gene in transgenic plants provides new insights into its role in the nitrate regulation of root development. Plant Cell Physiol 53:1003-1016

Gansel X, Munos S, Tillard P, Gojon A (2001) Differential regulation of the $\mathrm{NO}_{3}{ }^{-}$and $\mathrm{NH}_{4}{ }^{+}$transporter genes AtNrt2.1 and AtAmt1.1 in Arabidopsis: relation with longdistance and local controls by $\mathrm{N}$ status of the plant. Plant $\mathrm{J}$ 26:143-155

Gazzarini S, Lejay L, Gojon A, Ninnemann O, Frommer WB (1999) Three functional transporters for constitutive, diurnally regulated and starvation-induced uptake of ammonium into Arabidopsis roots. Plant Cell 11:937-947

Geiger D, Scherzer S, Mumm P, Stange A, Marten I, Bauer H, Ache P, Matschi S, Liese A, Al-Rasheid KA, Romeis T, Hedrich R (2009) Activity of guard cell anion channel SLAC1 is controlled by drought-stress signaling kinasephosphatase pair. Proc Natl Acad Sci USA 106:2142521430

Gifford ML, Dean A, Gutierrez RA, Coruzzi GM, Birnbaum KD (2008) Cell-specific nitrogen responses mediate developmental plasticity. Proc Natl Acad Sci USA 105:803-808

Girin T, Lejay L, Wirth J, Widiez T, Palenchar PM, Nazoa P, Touraine B, Gojon A, Lepetit M (2007) Identification of a $150 \mathrm{bp}$ cis-acting element of the AtNRT2.1 promoter involved in the regulation of gene expression by the $\mathrm{N}$ and $\mathrm{C}$ status of the plant. Plant Cell Environ 30:1366-1380 
Girin T, El-Kafafi E-S, Widiez T, Erban A, Hubberten HM, Kopka J, Hoefgen R, Gojon A, Lepetit M (2010) Identification of arabidopsis mutants impaired in the systemic regulation of root nitrate uptake by the nitrogen status of the plant. Plant Physiol 153:1250-1260

Gojon A, Dapoigny L, Lejay L, Tillard P, Rufty TW (1998) Effects of genetic modification of nitrate reductase expression on ${ }^{15} \mathrm{NO}_{3}{ }^{-}$uptake and reduction in Nicotiana plants. Plant Cell Environ 21:43-53

Gojon A, Nacry P, Davidian JC (2009) Root uptake regulation: a central process for NPS homeostasis in plants. Curr Opin Plant Biol 12:328-338

Gojon A, Krouk G, Perrine-Walker F, Laugier E (2011) Nitrate transceptor(s) in plants. J Exp Bot 62:2299-2308

Good AG, Shrawat AK, Muench DG (2004) Can less yield more? Is reducing nutrient input into the environment compatible with maintaining crop production? Trends Biotech 22:245-252

Gross M (2012) We need to talk about nitrogen. Curr Biol 22: R1-R4

Hachiya T, Mizokami Y, Miyata K, Tholen D, Watanabe CK, Noguchi K (2011) Evidence for a nitrate-independent function of the nitrate sensor NRT1.1 in Arabidopsis thaliana. J Plant Res 124:425-430

Hamburger D, Rezzonico E, MacDonald-Comber Petétot J, Somerville C, Poirier Y (2002) Identification and characterization of the Arabidopsis $\mathrm{PHOl}$ gene involved in phosphate loading to the xylem. Plant Cell 14:889-902

Hermans C, Hammond JP, White PJ, Verbruggen N (2006) How do plants respond to nutrient shortage by biomass allocation? Trends Plant Sci 11:610-617

Hinsinger P, Betencourt E, Bernard L, Brauman A, Plassard C, Shen J, Tang X, Zhang F (2011) P for two, sharing a scarce resource: soil phosphorus acquisition in the rhizosphere of intercropped species. Plant Physiol 156:1078-1086

Ho CH, Lin SH, Hu HC, Tsay YF (2009) CHL1 functions as a nitrate sensor in plants. Cell 138:1184-1194

Hodge A, Stewart J, Robinson D, Griffiths BS, Fitter AH (1998) Root proliferation, soil fauna and plant nitrogen capture from nutrient-rich patches in soil. New Phytol 139:479494

Hodge A, Robinson D, Griffiths BS, Fitter AH (1999) Why plants bother: root proliferation results in increased nitrogen capture from an organic patch when two grasses compete. Plant Cell Environ 22:811-820

Hodge A, Stewart J, Robinson D, Griffiths BS, Fitter AH (2000) Competition between roots and soil micro-organisms for nutrients from nitrogen-rich patches of varying complexity. J Ecol 88:150-164

Hoque MS, Masle J, Udvardi MK, Ryan PR, Upadhyaya NM (2006) Over-expression of the rice OsAMT1-1 gene increases ammonium uptake and content, but impairs growth and development of plants under high ammonium nutrition. Funct Plant Biol 33:153-163

Hu HC, Wang YY, Tsay YF (2009) AtCIPK8, a CBL-interacting protein kinase, regulates the low-affinity phase of the primary nitrate response. Plant J 57:264-278

Huang NC, Chiang CS, Crawford NM, Tsay YF (1996) CHL1 encodes a component of the low-affinity nitrate uptake system in Arabidopsis and shows cell type-specific expression in roots. Plant Cell 8:2183-2191
Huang NC, Liu KH, Lo HJ, Tsay YF (1999) Cloning and functional characterization of an Arabidopsis nitrate transporter gene that encodes a constitutive component of lowaffinity uptake. Plant Cell 11:1381-1392

Imsande J, Touraine B (1994) N demand and the regulation of nitrate uptake. Plant Physiol 105:3-7

Ishikawa S, Ito Y, Sato Y, Fukaya Y, Takahashi M, Morikawa H, Ohtake N, Ohyama T, Sueyoshi K (2009) Two-component high-affinity nitrate transport system in barley: membrane localization, protein expression in roots and a direct protein-protein interaction. Plant Biotechnol 26:197-205

Jackson WA, Volk RJ, Tucker TC (1972) Apparent induction of nitrate uptake in nitrate-depleted plants. Agron J 64:518-528

Jones DL, Shannon D, Junvee-Fortune T, Farrarc JF (2005) Plant capture of free amino acids is maximized under high soil amino acid concentrations. Soil Biol Biochem 37:179-181

Kaiser BN, Rawat SR, Siddiqi MY, Masle J, Glass AD (2002) Functional analysis of an Arabidopsis T-DNA "Knockout" of the high-affinity $\mathrm{NH}_{4}{ }^{+}$transporter AtAMT1-1. Plant Physiol 130:1263-1275

Kanno Y, Hanada A, Chiba Y, Ichikawa T, Nakazawa M, Matsui M, Koshiba T, Kamiya Y, Seo M (2012) Identification of an abscisic acid transporter by functional screening using the receptor complex as a sensor. Proc Natl Acad Sci U S A 109(24):9653-9658

Kant S, Peng M, Rothstein SJ (2011) Genetic regulation by NLA and microRNA827 for maintaining nitratedependent phosphate homeostasis in Arabidopsis. PLoS Genet 7:e1002021

Kawashima CG, Yoshimoto N, Maruyama-Nakashita A, Tsuchiya YN, Saito K, Takahashi H, Dalmay T (2009) Sulphur starvation induces the expression of microRNA395 and one of its target genes but in different cell types. Plant J 57:313-321

Kiba T, Kudo T, Kojima M, Sakakibara H (2011) Hormonal control of nitrogen acquisition: roles of auxin, abscisic acid, and cytokinin. J Exp Bot 62:1399-1409

Kiba T, Feria-Bourrellier AB, Lafouge F, Lezhneva L, BoutetMercey S, Orsel M, Bréhaut V, Miller A, Daniel-Vedele F, Sakakibara H, Krapp A (2012) The Arabidopsis nitrate transporter NRT2.4 plays a double role in roots and shoots of nitrogen-starved plants. Plant Cell 24:245-258

King BJ, Siddiqi MY, Ruth TJ, Warner RL, Glass A (1993) Feedback regulation of nitrate influx in barley roots by nitrate, nitrite, and ammonium. Plant Physiol 102:1279-1286

Kojima S, Bohner A, Gassert B, Yuan L, von Wiren N (2007) AtDUR3 represents the major transporter for high-affinity urea transport across the plasma membrane of nitrogendeficient Arabidopsis roots. Plant J 52:30-40

Kotur Z, Mackenzie N, Ramesh S, Tyerman SD, Kaiser BN, Glass ADM (2012) Nitrate transport capacity of the Arabidopsis thaliana NRT2 family members and their interactions with AtNAR2.1. New Phytol 194:724-731

Krapp A, Fraisier V, Scheible W-R, Quesada A, Gojon A, Stitt M, Caboche M, Daniel-Vedele F (1998) Expression studies of Nrt2;1 Np, a putative high-affinity nitrate transporter: evidence for its role in nitrate uptake. Plant J 14:723-731

Krouk G, Tillard P, Gojon A (2006) Regulation of the highaffinity $\mathrm{NO}_{3}{ }^{-}$Uptake System by a NRT1.1-mediated " $\mathrm{NO}_{3}{ }^{-}$demand" signalling in Arabidopsis. Plant Physiol 142:1075-1086 
Krouk G, Crawford NM, Coruzzi GM, Tsay YF (2010a) Nitrate signaling: adaptation to fluctuating environments. Curr Opin Plant Biol 13:266-273

Krouk G, Lacombe B, Bielach A, Perrine-Walker F, Malinska K, Mounier E, Hoyerova K, Tillard P, Leon S, Ljung K, Zazimalova E, Benkova E, Nacry P, Gojon A (2010b) Nitrate-regulated auxin transport by NRT1.1 defines a mechanism for nutrient sensing in plants. Dev Cell 18:927-937

Krouk G, Ruffel S, Gutierrez RA, Gojon A, Crawford NM, Coruzzi GM, Lacombe B (2011) A framework integrating plant growth with hormones and nutrients. Trends Plant Sci 16:178-182

Kumar A, Silim SN, Okamoto M, Siddiqi MY, Glass AD (2003) Differential expression of three members of the AMT1 gene family encoding putative high-affinity $\mathrm{NH}_{4}{ }^{+}$transporters in roots of Oryza sativa subspecies indica. Plant Cell Environ 26:907-914

Kumar A, Kaiser BN, Siddiqi MY, Glass ADM (2006) Functional characterization of OSAMT1.1 overexpression lines of rice, Oryza sativa. Funct Plant Biol 33:339-346

Lainé P, Ourry A, Boucaud J (1995) Shoot control of nitrate uptake rates by roots of Brassica napus L.: effects of localized nitrate supply. Planta 196:77-83

Lanquar V, Loqué D, Hörmann F, Yuan L, Bohner A, Engelsberger WR, Lalonde S, Schulze WX, von Wirén N, Frommer WB (2009) Feedback inhibition of ammonium uptake by a phospho-dependent allosteric mechanism in Arabidopsis. Plant Cell 21:3610-3622

Laugier E, Bouguyon E, Mauriès A, Tillard P, Gojon A, Lejay L (2012) Regulation of high-affinity nitrate uptake in roots of Arabidopsis depends predominantly on posttranscriptional control of the NRT2.1/NAR2.1 transport system. Plant Physiol 158:1067-1078

Lauter FR, Ninnemann O, Bucher M, Riesmeier JW, Frommer WB (1996) Preferential expression of an ammonium transporter and of two putative nitrate transporters in root hairs of tomato. Proc Natl Acad Sci USA 93:8139-8144

Lee RB (1993) Control of net uptake of nutrients by regulation of influx in barley plants recovering from nutrient deficiency. Ann Bot 72:223-230

Lee YH, Foster J, Chen J, Voll LM, Weber AP, Tegeder M (2007) AAP1 transports uncharged amino acids into roots of Arabidopsis. Plant J 50:305-319

Lehmann S, Gumy C, Blatter E, Boeffel S, Fricke W, Rentsch D (2011) In planta function of compatible solute transporters of the AtProT family. J Exp Bot 62:787-796

Lejay L, Tillard P, Lepetit M, Olive F, Filleur S, Daniel-Vedele F, Gojon A (1999) Molecular and functional regulation of two $\mathrm{NO}_{3}{ }^{-}$uptake systems by $\mathrm{N}$ - and $\mathrm{C}$-status of Arabidopsis plants. Plant J 18:509-519

Lesuffleur F, Paynel F, Bataille MP, Le Deunff E, Cliquet JB (2007) Root amino acid exudation: measurement of high efflux rates of glycine and serine from six different plant species. Plant Soil 294:235-246

Li W, Wang Y, Okamoto M, Crawford NM, Siddiqi MY, Glass AD (2007) Dissection of the AtNRT2.1:AtNRT2.2 inducible high-affinity nitrate transporter gene cluster. Plant Physiol 143:425-433

Li JY, Fu YL, Pike SM, Bao J, Tian W, Zhang Y, Chen CZ, Zhang Y, Li HM, Huang J, Li LG, Schroeder JI,
Gassmann W, Gong JM (2010) The Arabidopsis nitrate transporter NRT1.8 functions in nitrate removal from the xylem sap and mediates cadmium tolerance. Plant Cell 22:1633-1646

Lima JE, Kojima S, Takahashi H, von Wirén N (2010) Ammonium triggers lateral root branching in Arabidopsis in an AMMONIUM TRANSPORTER1;3-dependent manner. Plant Cell 22:3621-3633

Lin CM, Koh S, Stacey G, Yu SM, Lin TY, Tsay YF (2000) Cloning and functional characterization of a constitutively expressed nitrate transporter gene, OsNRT1, from rice. Plant Physiol 122:379-388

Linkohr BI, Williamson LC, Fitter AH, Leyser HM (2002) Nitrate and phosphate availability and distribution have different effects on root system architecture of Arabidopsis. Plant J 29:751-760

Liu KH, Tsay YF (2003) Switching between the two action modes of the dual-affinity nitrate transporter CHL1 by phosphorylation. EMBO J 22:1005-1013

Liu KH, Huang CY, Tsay YF (1999) CHL1 is a dual-affinity nitrate transporter of Arabidopsis involved in multiple phases of nitrate uptake. Plant Cell 11:865-874

Liu L-H, Ludewig U, Frommer WB, von Wiren N (2003a) AtDUR3 encodes a new type of high affinity urea $\mathrm{H}+$ symporter in Arabidopsis. Plant Cell 15:790-800

Liu L-H, Ludewig U, Gassert B, Frommer WB, von Wirén N (2003b) Urea transport by nitrogen-regulated tonoplast intrinsic TIP proteins in Arabidopsis. Plant Physiol 133:1220-1228

Liu TY, Chang CY, Chiou TJ (2009) The long-distance signaling of mineral macronutrients. Curr Opin Plant Biol $12: 312-319$

López-Bucio J, Hernández-Abreu E, Sánchez-Calderón L, Nieto-Jacobo MF, Simpson J, Herrera-Estrella L (2002) Phosphate availability alters architecture and causes changes in hormone sensitivity in the Arabidopsis root system. Plant Physiol 129:244-256

Loqué D, Yuan L, Kojima S, Gojon A, Wirth J, Gazzarrini S, Ishiyama K, Takahashi H, von Wiren N (2006) Additive contribution of AMT1;1 and AMT1;3 to high-affinity ammonium uptake across the plasma membrane of nitrogendeficient Arabidopsis roots. Plant J 48:522-534

Loqué D, Lalonde S, Looger LL, von Wiren N, Frommer WB (2007) A cytosolic trans-activation domain essential for ammonium uptake. Nature 446:195-198

Ludewig U, von Wirén N, Rentsch D, Frommer WB (2001) Rhesus factors and ammonium: a function in efflux? Genome Biol. 2, reviews 1010

Ludewig U, von Wirén N, Frommer WB (2002) Uniport of $\mathrm{NH}_{4}{ }^{+}$by the root hair plasma membrane ammonium transporter LeAMT1-1. J Biol Chem 277:13548-13555

Ludewig U, Wilken S, Wu B, Jost W, Obrdlik P, El Bakkoury M, Marini AM, Andre B, Hamacher T, Boles E, von Wiren N, Frommer WB (2003) Homo- and hetero-oligomerization of ammonium transporter-1 NH4 uniporters. J Biol Chem 278:45603-45610

Lynch JP (2007) Roots of the second green revolution. Aust J Bot 55(5):493-512

Lynch JP, Brown KM (2012) New roots for agriculture: exploiting the root phenome. Phylosophical Trans R Soc B-Biol Sci 367(1595):1598-1604 
Mack G, Tischner R (1994) Constitutive and inducible net $\mathrm{NH}_{4}{ }^{+}$ uptake of Barley (Hordeum-Vulgare L) seedlings. J Plant Physiol 144:351-357

Malagoli P, Laine P, Le Deunff E, Rossato L, Ney B, Ourry A (2004) Modeling nitrogen uptake in oilseed rape cv Capitol during a growth cycle using influx kinetics of root nitrate transport systems and field experimental data. Plant Physiol 134:388-400

Marschner H (1995) Mineral nutrition of higher plants, 2nd edn. Academic, London

Merigout P, Lelandais M, Bitton F, Renou JP, Briand X, Meyer C, Daniel-Vedele F (2008) Physiological and transcriptomic aspects of urea uptake and assimilation in Arabidopsis plants. Plant Physiol 147:1225-1238

Miller AJ, Fan X, Orsel M, Smith SJ, Wells DM (2007) Nitrate transport and signalling. J Exp Bot 58:2297-2306

Miyawaki K, Matsumoto-Kitano M, Kakimoto T (2004) Expression of cytokinin biosynthetic isopentenyltransferase genes in Arabidopsis: tissue specificity and regulation by auxin, cytokinin, and nitrate. Plant J 37:128-138

Morere-Le Paven MC, Viau L, Hamon A, Vandecasteele C, Pellizzaro A, Bourdin C, Laffont C, Lapied B, Lepetit M, Frugier F, Legros C, Limami AM (2011) Characterization of a dual-affinity nitrate transporter MtNRT1.3 in the model legume Medicago truncatula. J Exp Bot 62:5595-5605

Müller B, Touraine B (1992) Inhibition of $\mathrm{NO}_{3}{ }^{-}$uptake by various phloem-translocated amino acids in soybean seedlings. J Exp Bot 43:617-623

Munos S, Cazettes C, Fizames C, Gaymard F, Tillard P, Lepetit M, Lejay L, Gojon A (2004) Transcript profiling in the chll-5 mutant of Arabidopsis reveals a role of the nitrate transporter NRT1.1 in the regulation of another nitrate transporter, NRT2.1. Plant Cell 16:2433-2447

Näsholm T, Kielland K, Ganeteg U (2009) Uptake of organic nitrogen by plants. New Phytol 182:31-48

Nazoa P, Vidmar JJ, Tranbarger TJ, Mouline K, Damiani I, Tillard P, Zhuo D, Glass AD, Touraine B (2003) Regulation of the nitrate transporter gene AtNRT2.1 in Arabidopsis thaliana: responses to nitrate, amino acids and developmental stage. Plant Mol Biol 52:689-703

Nero D, Krouk G, Tranchina D, Coruzzi GM (2009) A system biology approach highlights a hormonal enhancer effect on regulation of genes in a nitrate responsive "biomodule". BMC Syst Biol 3:59

Neuhäuser B, Dynowsk IM, Mayer M, Ludewig U (2007) Regulation of $\mathrm{NH}_{4}{ }^{+}$transport by essential cross talk between AMT monomers through the carboxyl tails. Plant Physiol 143:1651-1659

Ninnemann O, Jauniaux J-C, Frommer WB (1994) Identification of a high affinity $\mathrm{NH}_{4}^{+}$transporter from plants. EMBO J 13:3464-3471

Nobbe F (1862) Uber die feinere Verästelung der Pflanzenwurzeln. Landwirtschaftlichen Versuchs-Stationen 4:212-224

Ohlen E, Larsson CM (1992) Nitrate assimilatory properties of barley grown under long-term N-limitation: effects of local nitrate supply in split-root cultures. Physiol Plant 85:9-16

Ohlund J, Nasholm T (2001) Growth of conifer seedlings on organic and inorganic nitrogen sources. Tree Physiol 18:1319-1326
Okamoto M, Vidmar JJ, Glass AD (2003) Regulation of NRT1 and NRT2 gene families of Arabidopsis thaliana: responses to nitrate provision. Plant Cell Physiol 44:304-317

Okamoto M, Kumar A, Li W, Wang Y, Siddiqi MY, Crawford NM, Glass AD (2006) High-affinity nitrate transport in roots of Arabidopsis depends on expression of the NAR2-like gene AtNRT3.1. Plant Physiol 140:1036-1046

Orsel M, Krapp A, Daniel-Vedele F (2002) Analysis of the NRT2 nitrate transporter family in Arabidopsis. Structure and gene expression. Plant Physiol 129:886-896

Orsel M, Chopin F, Leleu O, Smith SJ, Krapp A, Daniel-Vedele F, Miller AJ (2006) Characterization of a two-component high-affinity nitrate uptake system in Arabidopsis. Physiology and protein-protein interaction. Plant Physiol 142:1304-1317

Pages L (2011) Links between root developmental traits and foraging performance. Plant Cell Environ 34(10):1749-1760

Palmer SJ, Berridge DM, McDonald AJS, Davies WJ (1996) Control of leaf expansion in sunflower (Helianthus annuus L.) by nitrogen nutrition. J Exp Bot 47:359-368

Pant BD, Buhtz A, Kehr J, Scheible WR (2008) MicroRNA399 is a long-distance signal for the regulation of plant phosphate homeostasis. Plant J 53:731-738

Pant BD, Musialak-Lange M, Nuc P, May P, Buhtz A, Kehr J, Walther DF, Scheible WR (2009) Identification of nutrientresponsive Arabidopsis and rapeseed microRNAs by comprehensive real-time polymerase chain reaction profiling and small RNA sequencing. Plant Physiol 150:1541-1555

Paynel F, Murray PJ, Cliquet JB (2001) Root exudates: a pathway for short-term $\mathrm{N}$ transfer from clover and rye-grass. Plant Soil 229:235-243

Phillips DA, Fox TC, King MD, Bhuvaneswari TV, Teuber LR (2004) Microbial products trigger amino acid exudation from plant roots. Plant Physiol 136:2887-2894

Phillips DA, Fox TC, Six J (2006) Root exudation (net efflux of amino acids) may increase rhizodeposition under elevated $\mathrm{CO}_{2}$. Glob Chang Biol 12:561-567

Plett D, Toubia J, Garnett T, Tester M, Kaiser BN, Baumann U (2010) Dichotomy in the NRT gene families of dicots and grass species. PLoS One 5:e15289

Poirier Y, Thoma S, Somerville C, Schiefelbein J (1991) A mutant of Arabidopsis deficient in xylem loading of phosphate. Plant Physiol 97:1087-1093

Radin JW, Eidenbock MP (1986) Carbon accumulation during photosynthesis in leaves of nitrogen- and phosphorusstressed cotton. Plant Physiol 82:869-871

Rahayu YS, Walch-Liu P, Neumann G, Romheld V, von Wiren N, Bangerth F (2005) Root-derived cytokinins as longdistance signals for $\mathrm{NO}_{3}{ }^{-}$induced stimulation of leaf growth. J Exp Bot 56:1143-1152

Rawat SR, Silim SN, Kronzucker HJ, Siddiqi MY, Glass AD (1999) AtAMT1 gene expression and $\mathrm{NH}_{4}{ }^{+}$uptake in roots of Arabidopsis thaliana: evidence for regulation by root glutamine levels. Plant J 19:143-152

Reinhold L, Kaplan A (1984) Membrane transport of sugars and amino acids. Ann Rev Plant Physiol 35:45-83

Remans T, Nacry P, Pervent M, Filleur S, Diatloff E, Mounier E, Tillard P, Forde BG, Gojon A (2006) The Arabidopsis NRT1.1 transporter participates in the signaling pathway triggering root colonization of nitrate-rich patches. Proc Natl Acad Sci USA 103:19206-19211 
Rentsch D, Schmidt S, Tegeder M (2007) Transporters for uptake and allocation of organic nitrogen compounds in plants. FEBS Lett 581:2281-2289

Robinson D (1994) The responses of plants to non-uniform supplies of nutrients. New Phytol 127:635-674

Robinson D, Hodge A, Griffiths BS, Fitter AH (1999) Plant root proliferation in nitrogen-rich patches confers competitive advantage. Proc R Soc Lond B Biol 265:431-435

Rothstein SJ (2007) Returning to our roots: making plant biology research relevant to future challenges in agriculture. Plant Cell 19:2695-2699

Rouached H, Stefanovic A, Secco D, Bulak Arpat A, Gout E, Bligny R, Poirier Y (2011) Uncoupling phosphate deficiency from its major effects on growth and transcriptome via PHO1 expression in Arabidopsis. Plant J 65:557-570

Rubin G, Tohge T, Matsuda F, Saito K, Scheible WR (2009) Members of the LBD family of transcription factors repress anthocyanin synthesis and affect additional nitrogen responses in Arabidopsis. Plant Cell 21(11):3567-3584

Rubio V, Bustos R, Irigoyen ML, Cardona-Lopez X, RojasTriana M, Paz-Ares J (2009) Plant hormones and nutrient signaling. Plant Mol Biol 69:361-373

Ruffel S, Freixes S, Balzergue S, Tillard P, Jeudy C, MartinMagniette ML, van der Merwe MJ, Kakar K, Gouzy J, Fernie AR, Udvardi M, Salon C, Gojon A, Lepetit M (2008) Systemic signaling of the plant nitrogen status triggers specific transcriptome responses depending on the nitrogen source in Medicago truncatula. Plant Physiol 146:2020-2035

Ruffel S, Krouk G, Ristova D, Shasha D, Birnbaum KD, Coruzzi GM (2011) Nitrogen economics of root foraging: transitive closure of the nitrate-cytokinin relay and distinct systemic signaling for $\mathrm{N}$ supply vs. demand. Proc Natl Acad Sci USA 108:18524-18529

Rufty TW, Huber SC, Volk RJ (1988) Alterations in leaf carbohydrate metabolism in response to nitrogen stress. Plant Physiol 88:725-730

Sakakibara H, Suzuki M, Takei K, Deji A, Taniguchi M, Sugiyama T (1998) A response-regulator homologue possibly involved in nitrogen signal transduction mediated by cytokinin in maize. Plant J 14:337-344

Sakakibara H, Takei K, Hirose N (2006) Interactions between nitrogen and cytokinin in the regulation of metabolism and development. Trends Plant Sci 11:440-448

Samuelson ME, Larsson CM (1993) Nitrate regulation of zeatin riboside levels in barley roots: effects of inhibitors of $\mathrm{N}$ assimilation and comparison with ammonium. Plant Sci 93:77-84

Santi S, Locci G, Monte R, Pinton R, Varanini Z (2003) Induction of nitrate uptake in maize roots: expression of a putative high-affinity nitrate transporter and plasma membrane H+-ATPase isoforms. J Exp Bot 54:1851-1864

Sasaki T, Mori IC, Furuichi T, Munemasa S, Toyooka K, Matsuoka K, Murata Y, Yamamoto Y (2010) Closing plant stomata requires a homologue of an aluminium-activated malate transporter. Plant Cell Physiol 51:354-365

Scheible WR, Morcuende R, Czechowski T, Fritz C, Osuna D, Palacios-Rojas N, Schindelasch D, Thimm O, Udvardi MK, Stitt M (2004) Genome-wide reprogramming of primary and secondary metabolism, protein synthesis, cellular growth processes, and the regulatory infrastructure of
Arabidopsis in response to nitrogen. Plant Physiol 136:2483-2499

Schimel JP, Chapin FS (1996) Tundra plant uptake of amino acid and $\mathrm{NH}_{4}^{+}$nitrogen in situ: plants compete well for amino acid N. Ecology 77:2142-2147

Schobert C, Komor E (1987) Amino acid uptake by Ricinus communis roots: characterization and physiological significance. Plant Cell Environ 10:493-500

Segonzac C, Boyer JC, Ipotesi E, Szponarski W, Tillard P, Touraine B, Sommerer N, Rossignol M, Gibrat R (2007) Nitrate efflux at the root plasma membrane: identification of an Arabidopsis excretion transporter. Plant Cell 19:3760-3777

Signora L, De Smet I, Foyer CH, Zhang H (2001) ABA plays a central role in mediating them regulatory effects of nitrate on root branching in Arabidopsis. Plant J 28:655-662

Sohlenkamp C, Shelden M, Howitt S, Udvardi M (2000) Characterization of Arabidopsis AtAMT2, a novel ammonium transporter in plants. FEBS Lett 467:273-278

Sonoda Y, Ikeda A, Saiki S, von Wirén N, Yamaya T, Yamaguchi J (2003a) Distinct expression and function of three ammonium transporter genes (OsAMT1;1-1;3) in rice. Plant Cell Physiol 44:726-734

Sonoda Y, Ikeda A, Saiki S, Yamaya T, Yamaguchi J (2003b) Feedback regulation of the ammonium transporter gene family $A M T 1$ by glutamine in rice. Plant Cell Physiol 44:1396-1402

Stitt M (1999) Nitrate regulation of metabolism and growth. Cur Opin Plant Biol 2:178-186

Suenaga A, Moriya K, Sonoda Y, Ikeda A, Von Wirén N, Hayakawa T, Yamaguchi J, Yamaya T (2003) Constitutive expression of a novel-type ammonium transporter OSAMT2 in rice plants. Plant Cell Physiol 44:206-211

Svennerstam H, Ganeteg U, Bellini C, Näsholm T (2007) Comprehensive screening of Arabidopsis mutants suggests the lysine histidine transporter 1 to be involved in plant uptake of amino acids. Plant Physiol 143:1853-1860

Svennerstam H, Ganeteg U, Näsholm T (2008) Root uptake of cationic amino acids by Arabidopsis depends on functional expression of amino acid permease 5. New Phytol 180:620630

Svistoonoff S, Creff A, Reymond M, Sigoillot-Claude C, Ricaud L, Blanchet A, Nussaume L, Desnos T (2007) Root tip contact with low-phosphate media reprograms plant root architecture. Nat Genet 39:792-796

Takei K, Sakakibara H, Taniguchi M, Sugiyama T (2001) Nitrogen-dependent accumulation of cytokinins in root and the translocation to leaf: implication of cytokinin species that induces gene expression of maize response regulator. Plant Cell Physiol 42:85-93

Takei K, Ueda N, Aoki K, Kuromori T, Hirayama T, Shinozaki K, Yamaya T, Sakakibara H (2004) AtIPT3 is a key determinant of nitrate-dependent cytokinin biosynthesis in Arabidopsis. Plant Cell Physiol 45:1053-1062

Taniguchi M, Kiba T, Sakakibara H, Ueguchi C, Mizuno T, Sugiyama T (1998) Expression of Arabidopsis response regulator homologs is induced by cytokinins and nitrate. FEBS Lett 429:259-262

Tegeder M (2012) Transporters for amino acids in plant cells: some functions and many unknowns. Curr Opin Plant Biol 15(3):315-321 
Thornton B, Robinson D (2005) Uptake and assimilation of nitrogen from solutions containing multiple $\mathrm{N}$ sources. Plant Cell Environ 28:813-821

Tian QY, Chen FJ, Zhang FS, Mi GH (2005) Possible involvement of cytokinin in nitrate-mediated root growth in maize. Plant Soil 100:1-12

Tian Q, Chen F, Liu J, Zhang F, Mi G (2008) Inhibition of maize root growth by high nitrate supply is correlated with reduced IAA levels in roots. J Plant Physiol 165:942-951

Tian QY, Sun P, Zhang W-H (2009) Ethylene is involved in nitrate-dependent root growth and branching in Arabidopsis thaliana. New Phytol 184:918-931

Tillard P, Passama L, Gojon A (1998) Are phloem amino acids involved in the shoot to root control of $\mathrm{NO}_{3}{ }^{-}$uptake in Ricinus communis plants? J Exp Bot 49:1371-1379

Tilman D, Cassman KG, Matson PA, Naylor R, Polasky S (2002) Agricultural sustainability and intensive production practices. Nature 418:671-677

Tong Y, Zhou JJ, Li Z, Miller AJ (2005) A two-component highaffinity nitrate uptake system in barley. Plant J 41:442-450

Touraine B, Glass AD (1997) $\mathrm{NO}_{3}{ }^{-}$and $\mathrm{ClO}_{3}{ }^{-}$fluxes in the chl1-5 mutant of Arabidopsis thaliana. Does the CHL1-5 gene encode a low-affinity $\mathrm{NO}_{3}{ }^{-}$transporter? Plant Physiol 114:137-144

Trueman LJ, Richardson A, Forde BG (1996) Molecular cloning of higher plant homologues of the high-affinity nitrate transporters of Chlamydomonas reinhardtii and Aspergillus nidulans. Gene 175:223-231

Tsay YF, Schroeder JI, Feldmann KA, Crawford NM (1993) The herbicide sensitivity gene CHL1 of Arabidopsis encodes a nitrate-inducible nitrate transporter. Cell 72:705-713

Tsay YF, Chiu CC, Tsai CB, Ho CH, Hsu PK (2007) Nitrate transporters and peptide transporters. FEBS Lett 581:2290-2300

Tsay YF, Ho CH, Chen HY, Lin SH (2011) Integration of nitrogen and potassium signaling. Ann Rev Plant Biol 62:207-226

van Vuuren MMI, Robinson D, Griffiths BS (1996) Nutrient inflow and root proliferation during the exploitation of a temporally and spatially discrete source of nitrogen in soil. Plant Soil 178:185-192

Vidal EA, Araus V, Lu C, Parry G, Green PJ, Coruzzi GM, Gutierrez RA (2010) Nitrate-responsive miR393/AFB3 regulatory module controls root system architecture in Arabidopsis thaliana. Proc Natl Acad Sci USA 107:4477-4482

Vidmar JJ, Zhuo D, Siddiqi MY, Schjoerring JK, Touraine B, Glass AD (2000) Regulation of high-affinity nitrate transporter genes and high-affinity nitrate influx by nitrogen pools in roots of barley. Plant Physiol 123:307-318

von Wirén N, Merrick M (2004) Regulation and function of ammonium carriers in bacteria, fungi and plants. Top Curr Genet 9:95-120

von Wirén N, Gazzarrini S, Gojon A, Frommer WB (2000a) The molecular physiology of ammonium uptake and retrieval. Curr Opin Plant Biol 3:254-261

von Wirén N, Lauter F-R, Ninnemann O, Gillissen B, WalchLiu P, Engels C, Jost W, Frommer WB (2000b) Differential regulation of three functional ammonium transporter genes by nitrogen in root hairs and by light in leaves of tomato. Plant J 21:167-175

Wagner B, Beck E (1993) Cytokinins in the perennial herb Urtica dioica L. as influenced by its nitrogen status. Planta 190:511-518
Walch-Liu P, Forde BG (2008) Nitrate signalling mediated by the NRT1.1 nitrate transporter antagonises L-glutamateinduced changes in root architecture. Plant J 54:820-828

Walch-Liu P, Filleur S, Gan Y, Forde BG (2005) Signaling mechanisms integrating root and shoot responses to changes in the nitrogen supply. Photosynth Res 83:239250

Walch-Liu P, Ivanov II, Filleur S, Gan Y, Remans T, Forde BG (2006) Nitrogen regulation of root branching. Ann Bot 97:875-881

Wang YY, Tsay YF (2011) Arabidopsis nitrate transporter NRT1.9 is important in phloem nitrate transport. Plant Cell 23:1945-1957

Wang MY, Siddiqi MY, Ruth TJ, Glass ADM (1993) Ammonium uptake by rice roots. I. Fluxes and sucellular distribution of ${ }^{13} \mathrm{NH}_{4}^{+}$. Plant Physiol 103:1249-1258

Wang R, Liu D, Crawford NM (1998) The Arabidopsis CHL1 protein plays a major role in high-affinity nitrate uptake. Proc Natl Acad Sci USA 95:15134-15139

Wang R, Guegler K, LaBrie ST, Crawford NM (2000) Genomic analysis of a nutrient response in Arabidopsis reveals diverse expression patterns and novel metabolic and potential regulatory genes induced by nitrate. Plant Cell 12:14911510

Wang R, Okamoto M, Xing X, Crawford NM (2003) Microarray analysis of the nitrate response in Arabidopsis roots and shoots reveals over 1,000 rapidly responding genes and new linkages to glucose, trehalose-6-phosphate, iron, and sulfate metabolism. Plant Physiol 132:556-567

Wang R, Tischner R, Gutierrez RA, Hoffman M, Xing X, Chen M, Coruzzi G, Crawford NM (2004) Genomic analysis of the nitrate response using a nitrate reductase-null mutant of Arabidopsis. Plant Physiol 136:2512-2522

Wang W-H, Köhler B, Cao F-Q, Liu L-H (2008) Molecular and physiological aspects of urea transport in higher plants. Plant Sci 175:467-477

Wang R, Xing X, Wang Y, Tran A, Crawford NM (2009) A genetic screen for nitrate regulatory mutants captures the nitrate transporter gene NRT1.1. Plant Physiol 151:472-478

Wang YY, Hsu PK, Tsay YF (2012) Uptake, allocation and signaling of nitrate. Trends Plant Sci 17(8):458-467

West CE, Waterworth WM, Stephens SM, Smith CP, Bray CM (1998) Cloning and functional characterization of a peptide transporter expressed in the scutellum of barley. Plant $\mathrm{J}$ 15:221-229

Widiez T, El Kafafi e S, Girin T, Berr A, Ruffel S, Krouk G, Vayssières A, Shen WH, Coruzzi GM, Gojon A, Lepetit M (2011) High nitrogen insensitive 9 (HNI9)-mediated systemic repression of root $\mathrm{NO}_{3}{ }^{-}$uptake is associated with changes in histone methylation. Proc Natl Acad Sci USA 108:13329-13334

Williamson LC, Ribrioux SPCP, Fitter AH, Leyser HMO (2001) Phosphate availability regulates root system architecture in Arabidopsis. Plant Physiol 126

Wirth J, Chopin F, Santoni V, Viennois G, Tillard P, Krapp A, Lejay L, Daniel-Vedele F, Gojon A (2007) Regulation of root nitrate uptake at the NRT2.1 protein level in Arabidopsis thaliana. J Biol Chem 282:23541-23552

Witte C-P (2011) Urea metabolism in plants. Plant Sci 180:431-438

$\mathrm{Xu}$ G, Fan X, Miller AJ (2012) Plant nitrogen assimilation and use efficiency. Annu Rev Plant Biol 63:153-182 
Yendrek CR, Lee YC, Morris V, Liang Y, Pislariu CI, Burkart G, Meckfessel MH, Salehin M, Kessler H, Wessler H, Lloyd M, Lutton H, Teillet A, Sherrier DJ, Journet EP, Harris JM, Dickstein R (2010) A putative transporter is essential for integrating nutrient and hormone signaling with lateral root growth and nodule development in Medicago truncatula. Plant J 62:100-112

Yoh SM, Lucas JS, Jones KA (2008) The Iws1:Spt6:CTD complex controls cotranscriptional mRNA biosynthesis and HYPB/Setd2-mediated histone H3K36 methylation. Genes Dev 22:3422-3434

Yong Z, Kotur Z, Glass AD (2010) Characterization of an intact two-component high-affinity nitrate transporter from Arabidopsis roots. Plant J 63:739-748

Yuan L, Loqué D, Kojima S, Rauch S, Ishiyama K, Inoue E, Takahashi H, von Wiren N (2007) The organization of high-affinity ammonium uptake in Arabidopsis roots depends on the spatial arrangement and biochemical properties of AMT1-type transporters. Plant Cell 19:2636-2652

Yuan L, Graff L, Loqué D, Kojima S, Tsuchiya YN, Takahashi H, von Wirén N (2009) AtAMT1;4, a pollen-specific high-affinity ammonium transporter of the plasma membrane in Arabidopsis. Plant Cell Physiol 50:13-25

Zhang H, Forde BG (1998) An Arabidopsis MADS box gene that controls nutrient-induced changes in root architecture. Science 279:407-409

Zhang H, Forde BG (2000) Regulation of Arabidopsis root development by nitrate availability. J Exp Bot 51:51-59

Zhang H, Jennings A, Barlow PW, Forde BG (1999) Dual pathways for regulation of root branching by nitrate. Proc Natl Acad Sci USA 96:6529-6534

Zhang H, Rong H, Pilbeam D (2007) Signalling mechanisms underlying the morphological responses of the root system to nitrogen in Arabidopsis thaliana. J Exp Bot 58:2329-2338

Zhao M, Ding H, Zhu JK, Zhang F, Li WX (2011) Involvement of miR169 in the nitrogen-starvation responses in Arabidopsis. New Phytol 190:906-915

Zhou JJ, Fernandez E, Galvan A, Miller AJ (2000) A high affinity nitrate transport system from Chlamydomonas requires two gene products. FEBS Lett 466:225-227

Zhuo D, Okamoto M, Vidmar JJ, Glass AD (1999) Regulation of a putative high-affinity nitrate transporter $(\mathrm{Nrt} 2 ; 1 \mathrm{At})$ in roots of Arabidopsis thaliana. Plant J 17:563-568 